\author{
UNIVERSidAde DE SÃo PAUlo \\ FFCLRP - DEPARTAMENTO DE FÍSICA \\ Pós-GraduaÇão em Física Aplicada À Medicina e Biologia
}

\title{
Caracterização do Dosímetro de Antraceno para Radiação de Fótons Radioterápica
}

\author{
Caroline Czelusniak
}

Dissertação apresentada à Faculdade de Filosofia, Ciências e Letras de Ribeirão Preto da Universidade de São Paulo, como parte das exigências para a obtenção do título de Mestre em Ciências. Área: Física Aplicada à Medicina e Biologia.

Ribeirão Preto - SP

2011 


\section{CAROLINE CZELUSNIAK}

\section{Caracterização do Dosímetro de Antraceno para Radiação de Fótons Radioterápica}

Dissertação apresentada à Faculdade de Filosofia, Ciências e Letras de Ribeirão Preto da Universidade de São Paulo, como parte das exigências para a obtenção do título de Mestre em Ciências.

\section{Área de Concentração:}

Física Aplicada à Medicina e Biologia.

\section{Orientadora:}

Dra. Adelaide de Almeida.

Versão corrigida

Versão original disponível na FFCLRP-

Ribeirão Preto - SP 
Autorizo a reprodução e divulgação total ou parcial deste trabalho, por qualquer meio convencional ou eletrônico, para fins de estudo e pesquisa, desde que citada a fonte.

\section{FICHA CATALOGRÁFICA}

\section{Czelusniak, Caroline.}

Caracterização do Dosímetro de Antraceno para Radiação de Fótons Radioterápica / Caroline Czelusniak; Dra. Adelaide de Almeida, orientadora. Ribeirão Preto, 2011. 67 p.

Dissertação (Mestrado - Programa de Pós-Graduação em Física Aplicada à Medicina e Biologia) - Faculdade de Filosofia, Ciências e Letras de Ribeirão Preto da Universidade de São Paulo.

1. dosimetria. 2. antraceno. 3. cintilação. 4. radioterapia. 
Nome: Czelusniak, Caroline

Título: Caracterização do Dosímetro de Antraceno para Radiação de Fótons Radioterápica

Dissertação apresentada à Faculdade de Filosofia,

Ciências e Letras de Ribeirão Preto da

Universidade de São Paulo, como parte das exigências para a obtenção do título de Mestre em Ciências.

Aprovado em:

\section{Banca Examinadora}

Prof. Dr. :

Instituição:

Julgamento:

Assinatura:

Prof. Dr. :

Instituição:

Julgamento:

Assinatura:

Prof. Dr. :

Instituição:

Julgamento:

Assinatura: 
Aos meus pais. 


\section{AGRADECIMENTOS}

A minha orientadora Profa. Dra. Adelaide de Almeida pela orientação e ensinamentos para a realização deste trabalho;

Aos meus pais, Luiz e Eliane, e meus irmãos Luiz Eduardo e Fernando, pelo amor, confiança e incentivo;

A minha tia Regiane Silvestre Gatto pelo carinho e amizade;

Ao Lucas Sacchini Del Lama por toda a colaboração, não somente para este trabalho, desde minha entrada no mestrado;

Aos integrantes do grupo Radiare, especialmente Francisco Glaildo Almeida Sampaio, David Marçal Machado de Oliveira e Fernanda Cavalcante, pela amizade e ajuda;

Ao meu amigo Jonathan Cristiano Costa, pelas conversas sobre física e vida;

À Karina Fioravante pela amizade sem limites;

Ao físico Paulo C. D. Petchevist pela colaboração na realização dos experimentos e pelos ensinamentos;

Aos técnicos José Luiz Aziani e Sérgio Oliveira Bueno da Silva pela confecção dos porta amostras, e ao técnico Élcio Aparecido Navas pela ajuda na manutenção dos aparelhos eletrônicos;

Ao físico Marcos M. Vasques pela colaboração na realização das medidas de resolução espacial e ensinamentos;

Ao Rodrigo Rubo pelo empréstimo de material e compartilhamento de conhecimentos;

Ao Nivaldo Carlos da Silva da CNEN pela ajuda na obtenção de material;

Ao Professor Herenilton Paulino Oliveira pelo empréstimo das peneiras granulométricas;

À Metrobrás, ao físico Tiago Chaud de Paula e ao professor José Carlos Borges, pela disponibilização da fonte de ${ }^{137} \mathrm{Cs}$;

À CNPQ pelo apoio financeiro. 
"Seja você a mudança que quer ver no mundo." Mahatma Gandhi 


\section{RESUMO}

\section{CZELUSNIAK, C. Caracterização do Dosímetro de Antraceno para}

Radiação de Fótons Radioterápica. 2011. 67 p. Dissertação (Mestrado Programa de Pós-Graduação em Física Aplicada à Medicina e Biologia) - Faculdade de Filosofia, Ciências e Letras de Ribeirão Preto da Universidade de São Paulo. 2011.

A dosimetria na radioterapia é realizada periodicamente como parte do controle de qualidade tanto dos equipamentos como dos tratamentos dos pacientes. O dosímetro convencional utilizado para essa finalidade é a câmara de ionização, no entanto, ela pode apresentar limitações quando se necessita de um dosímetro que possua resoluções espacial e temporal altas. Este trabalho tem como objetivo a caracterização do dosímetro de antraceno para radiação de fótons radioterápicos. O antraceno é um cristal orgânico cintilador com vantagens de ser praticamente equivalente à água e tecido mole em feixes radioterápicos e com possibilidade de possuir volume de detecção e tamanho pequenos, para utilizar em radiocirurgia e dosimetria in vivo. Neste trabalho, a caracterização do dosímetro de antraceno foi realizada obtendo-se o sinal de cintilação em função da sua granulosidade média, diâmetro da sua cápsula interna, dose absorvida, taxa de dose absorvida, energia do feixe de radiação e sua resolução espacial, sendo essa última realizada por três métodos diferentes relacionados e equivalentes: (função de espalhamento de borda (FEB), função de espalhamento linear (FEL) e função de transferência de modulação $(\mathrm{MTF}))$. Os feixes de fótons utilizados para as irradiações do cintilador foram os de ${ }^{60} \mathrm{Co}(1,25 \mathrm{MeV}),{ }^{137} \mathrm{Cs}(0,661 \mathrm{MeV})$ e raios X (energias efetivas de 28,4; 46,5; 48,$5 ; 94,0$ e 106,0 keV). A instrumentação utilizada para a detecção do sinal do cintilador foi composta por uma fibra óptica, fotomultiplicadora, fonte de alta 
tensão, eletrômetro e multímetro. Dos dados obtidos, a contribuição da radiação Cerenkov, produzida na fibra óptica, foi subtraída, e as seguintes características dos sinais resultantes puderam ser inferidas: quanto maior a granulosidade maior o sinal de cintilação detectado; a dependência do sinal com o diâmetro interno da sua cápsula aumenta proporcionalmente com o cubo do diâmetro; dependência linear do sinal com a dose absorvida; independência com a taxa de dose absorvida; dependência linear para baixas energias e independência para altas energia do feixe. Além disso, das resoluções espaciais encontradas pelos três métodos diferentes, aquela calculada pelo método MTF é a que mais se aproximou das dimensões do

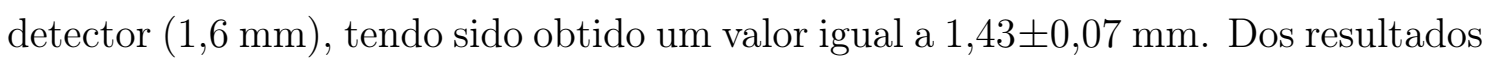
foi possível caracterizar o dosímetro de antraceno de modo que sua utilização em trabalhos futuros seja mais adequada.

Palavras-chave: 1. dosimetria. 2. antraceno. 3. cintilação. 4. radioterapia. 


\section{ABSTRACT}

\section{CZELUSNIAK, C. Anthracene Dosimeter Characterization under Radiotherapic}

Photons. 2011. 67 p. Dissertation (M.Sc. - Postgraduate program in Physics Applied to Medicine and Biology) - Faculty of Philosophy, Sciences and Letters, University of São Paulo. 2011.

New radiotherapy techniques such as intensity-modulated radiation therapy and stereotactic radiosurgery have increased the need for dosimeters that can provide measurements in real time with high spatial resolution. Organic scintillation dosimeters are able to measure with accuracy small radiation fields and fields with high gradients, besides having advantages such as water and soft tissue equivalence and the possibility to be used in vivo. Anthracene is an organic scintillator crystal with the highest known scintillation efficiency among organic scintillation materials. The objective of this work is to characterize the antracene as a dosimeter under radiotherapic photons energies, analysing its signal against average granulosity, intern capsule diameter, absorbed dose, absorbed dose rate, photon energy and its spatial resolution; with the last one analysed under three methods (edge spread function, line spread function and modulation transfer function). The photons energies used were $1.25 \mathrm{MeV}\left({ }^{60} \mathrm{Co}\right), 0.661 \mathrm{MeV}\left({ }^{137} \mathrm{Cs}\right.$ ) and X-rays (effective energies of $28.4 ; 46.5 ; 48.5 ; 94.0$ e $106.0 \mathrm{keV}$ ). The scintillation detection system consisted of an optical fiber with one end attached to the anthracene capsule and the other to a photomultiplier tube mantained by power supply followed by an electrometer. Once Cerenkov radiation occurs in the optical fiber, it was removed from the total scintillation signal trough the subtraction of the signal, taken irradiating the optical fiber without the anthracene attached to one of its extremity. From results obtained, one can infer that the dosimeter signal increases proportionally with 
average granulosity and intern capsule diameter. The signal is linearly dependent of absorbed dose, linearly dependent of low photons energies and independent for high photons energies, as well as independent of the absorbed dose rate. From the spatial resolution values obtained it was possible to infer that the one obtained through modulation transfer function, $1.43 \pm 0.07 \mathrm{~mm}$, was the one that approximated the most to the actual dosimeter physical size $(1.6 \mathrm{~mm})$. From the characteristics obtained with this work, we think that future projects involving the anthracene will be carried out more properly.

Key-words: 1. dosimetry. 2. anthracene. 3. scintillation. 4. radiotherapy. 


\section{LISTA DE FIGURAS}

1.1 Regiões onde os efeitos fotoelétrico, Compton e produção de pares são dominantes em função do número atômico efetivo do material e da energia dos fótons incidentes [1] . . . . . . . . . . . . 8

1.2 Comportamentos diferentes que um dosímetro pode apresentar do sinal em função da dose absorvida. . . . . . . . . . . . . . . . . 12

1.3 Níveis de energia de moléculas orgânicas com estrutura eletrônica $\pi$ [2]. 14

1.4 Coeficientes de atenuação mássico em função da energia dos fótons para o antraceno, PMMA, água e acrílico. . . . . . . . . . . 16

1.5 Coeficientes de atenuação mássico de energia em função da energia dos fótons para o antraceno, PMMA, água e tecido mole. . . . . . . . 17

1.6 Reflexão interna da luz em uma fibra óptica de índice degrau. . . . . 18

2.1 Esquema da irradiação do dosímetro de antraceno com sistema de detecção e leitura do sinal. . . . . . . . . . . . . . . . . . . . . 23

2.2 Suporte de acrílico que permite alinhar a fibra óptica com a cápsula do antraceno. . . . . . . . . . . . . . . . . . . . . . . 24

2.3 Peneiras granulométricas utilizadas para a separação dos grânulos de antraceno. . . . . . . . . . . . . . . . 26

2.4 Imagens com frequência de linhas por comprimento diferentes. . . . . 28

2.5 Resposta de um sistema a uma fenda praticamente infinitesimal. . . . 29

2.6 Esquema do sistema de irradiação do dosímetro de antraceno para obtenção do perfil de borda. . . . . . . . . . . . . . . . . . 30

2.7 Resposta de um detector ideal a uma descontinuidade. . . . . . . . . 30 
3.1 Relação entre o sinal conhecido de um sistema elétrico simples, lido diretamento no eletrômetro, e o detectado pelo multímetro conetado na saída do eletrômetro. . . . . . . . . . . . . . . . . . . . 33

3.2 Comportamento do sinal do antraceno em função da dimensão média dos grânulos. . . . . . . . . . . . . . . . . . . . 35

3.3 Comportamento do sinal do antraceno em função dos diâmetros internos de suas cápsulas. . . . . . . . . . . . . . . . . 36

3.4 Cone de aceitação da fibra óptica utilizada com abertura numérica de 0,5.(a) cápsula do dosímetro com diâmetro dentro do cone de aceitação e (b) com diâmetro maior que o cone de aceitação. . . . 36

3.5 Dependência do sinal do cintilador com a dose absorvida para feixes calibrados do ${ }^{60}$ Co. . . . . . . . . . . . . . . . . . . . . . 37

3.6 Dependência do sinal do cintilador com a taxa de dose absorvida, independente do quadrado da distância (foco-superfície) da fonte de ${ }^{60}$ Co. . . . . . . . . . . . . . . . . . . . . . . 38

3.7 Dependência do sinal do dosímetro cintilador com a energia do feixe de fótons. . . . . . . . . . . . . . . . . . . . . . . . 39

3.8 [Perfil do sinal do dosímetro de antraceno ao medir uma descontinuidade. . . . . . . . . . . . . . . . 4 40

3.9 Função de espalhamento de linha. . . . . . . . . . . . . . . . . . . . 40

3.10 Função de transferência de modulação. . . . . . . . . . . . . . . . . . 41 


\section{Lista DE ABReViaturas}

FEB Função de Espalhamento de Borda.

FEL Função de Espalhamento de Linha.

MTF Função de Transferência de Modulação (Modulation Transfer Function).

HPA Hidrocarboneto Policíclico Aromático.

DFS Distância Foco-Superfície.

DFD Distância Foco-Detector. 


\section{SUMÁRIO}

Lista de Figuras $\quad$ x

Lista de Figuras $\quad$ xi

Lista de Abreviaturas xiii

$\begin{array}{ll}\text { Introdução } & 2\end{array}$

1 Aspectos Teóricos $\quad 6$

1.1 Interações de Fótons com a Matéria . . . . . . . . . . . . . . . . . . . 7

Efeito Fotoelétrico . . . . . . . . . . . . . . 8

Efeito Compton ...................... . . 9

Produção de Pares . . . . . . . . . . . . . . . . . . . . . . . . . . 9

1.2 Coeficiente de Atenuação Mássico e Coeficiente de Absorção Mássico de Energia . . . . . . . . . . . . . . . . . . . . . . 10

1.3 Dosimetria . . . . . . . . . . . . . . . . . . 11

1.4 Cintilação . . . . . . . . . . . . . . . . . . . . . . . . . 13

1.5 Antraceno . . . . . . . . . . . . . . . . . . . 15

1.6 Fibras Ópticas . . . . . . . . . . . . . . . . . . . . . . . . . 18

1.7 Efeito Cerenkov . . . . . . . . . . . . . . . . . . . 19

2 Materiais e Métodos $\quad 22$

2.1 Materiais . . . . . . . . . . . . . . . . . 22

2.2 Métodos . . . . . . . . . . . . . . . . . . . 23

Verificação do Sistema Eletrônico . . . . . . . . . . . . . . . . . . 24

Detecção da cintilação . . . . . . . . . . . . . . . . . . . . . . . . . 24 
Relação Sinal-Ruído . . . . . . . . . . . . . . . . 25

Dependência do Sinal do Cintilador com a Granulosidade . . . . . . . 25

Dependência do Sinal do Cintilador com o Diâmetro Interno da Cápsula 26

Dependência do Sinal do Cintilador com a Dose Absorvida . . . . . . 26

Dependência do Sinal do Cintilador com a Taxa de Dose Absorvida . 27

Dependência Energética do Sinal do Cintilador . . . . . . . . . . . . . 27

Resolução Espacial do Dosímetro . . . . . . . . . . . . . . . . 28

3 Resultados e Discussões 33

3.1 Verificação do Sistema Eletrônico . . . . . . . . . . . . . . . . . . . . 33

Relação Eletrômetro-Multímetro . . . . . . . . . . . . . . 33

Relação Sinal-Ruído . . . . . . . . . . . . . . . 33

3.2 Caracterização do Dosímetro de Antraceno . . . . . . . . . . . . . . . 34

Dependência do Sinal do Cintilador com a Granulosidade . . . . . . . 34

Dependência do Sinal do Cintilador com o Diâmetro Interno da Cápsula 35

Dependência do Sinal do Cintilador com a Dose Absorvida . . . . . . 36

Dependência do Sinal do Cintilador com a Taxa de Dose Absorvida . 37

Dependência Energética do Sinal do Cintilador . . . . . . . . . . . . . 38

Resolução Espacial do Dosímetro . . . . . . . . . . . . . . . . . . . . 39

4 Conclusão $\quad 44$

$\begin{array}{ll}\text { Referências Bibliográficas } & 47\end{array}$

A Apêndice I - Cuidados em relação ao Antraceno 52

A.1 Controle de Exposição e Proteção Pessoal . . . . . . . . . . . . . . 52

A.2 Efeitos potenciais à saúde . . . . . . . . . . . . . . . 52

A.3 Medidas de Primeiros Socorros . . . . . . . . . . . . . . . . . 52 
INTRODUÇÃO 


\section{INTRODUÇÃO}

Um dos objetivos da radioterapia é destruir células tumorais através do uso de radiação ionizante, sem danificar tecidos saudáveis. Para alcançar este objetivo, os centros de radioterapia realizam procedimentos periodicamente para o controle de qualidade de seus equipamentos e tratamentos. Um dos parâmetros monitorados nessas análises é a dose absorvida, que é a energia que um feixe de radiação ionizante deposita em um meio por unidade de sua massa. Segundo protocolos internacionais, utilizados para o controle de qualidade dos tratamentos radioterápicos, a incerteza total da dose absorvida administrada ao paciente não deve ultrapassar $5 \%$ daquela prescrita pelo radioterapeuta [3]. As medidas dosimétricas são realizadas através de dosímetros, que são detectores de radiação capazes de fornecer uma leitura proporcional à dose absorvida no meio de interesse.

Os protocolos de dosimetria determinam a câmara de ionização como o principal detector a ser utilizado para a calibração de feixes. Apesar deste dosímetro ser eficiente nas avaliações dosimétricas para a radioterapia tradicional, ele possui um volume de detecção relativamente grande, sendo inapropriado para medidas em campos pequenos e campos com gradientes altos de dose. As técnicas modernas de tratamento radioterápico, como radioterapia estereotáxica, radioterapia com intensidade modulada e cyberknife, tem como finalidade conformar a dose de maneira mais próxima ao volume alvo evitando-se estruturas críticas, o que resulta em campos pequenos e gradientes altos de dose. Assim, dosímetros com resolução espacial e temporal alta são os mais adequados para a validação dessas técnicas de tratamento. Dentre eles, os cintiladores orgânicos são conhecidos por serem equivalentes à água e tecido mole, e podem possuir um volume de detecção e tamanho pequenos, o que possibilitaria a dosimetria in vivo [4-10].

A cintilação é o fenômeno pelo qual alguns materiais emitem luz após serem 
excitados por radiação ionizante [2]. Sua eficiência é caracterizada pela razão entre a energia total dos fótons emitidos pelo material cintilador e a energia total das partículas incidentes no material, i.e., a fração da energia incidente que é convertida em luz. O material utilizado neste trabalho é um hidrocarboneto policíclico aromático denominado antraceno $\left(\mathrm{C}_{14} \mathrm{H}_{10}\right)$. Este cintilador foi escolhido como objeto de estudo devido à sua equivalência à água para feixes radioterápicos e eficiência de cintilação alta, conhecida como a maior entre os cintiladores orgânicos [2]. Estudos do antraceno como detector de raios X e outras partículas de baixas energias podem ser encontrados a partir da década de 50 [11], [12]. O estudo realizado por Rubo em 2001 [13] mostrou a aplicabilidade do antraceno para a dosimetria na radioterapia de megavoltagem. O presente trabalho tem como objetivo principal realizar a caracterização do cintilador de antraceno como um dosímetro, iniciada por Rubo em 2001. Os objetivos específicos compreendem estudos das dependências do sinal detectado pelo dosímetro com a sua granulosidade, tamanho do diâmetro interno da sua cápsula cilíndrica, dose absorvida, taxa de dose absorvida, energia do feixe de radiação e resolução espacial.

Para realizar os estudos propostos, o sistema de deteç̧ão de cintilação consistiu de uma fibra óptica, com uma extremidade acoplada ao cintilador e a outra à uma fotomultiplicadora, uma fonte de alta tensão para alimentar a fotomultiplicadora, um eletrômetro e um multímetro conectado na saída desse. A irradiação da fibra óptica pode adicionar uma componente indesejada ao sinal do cintilador devida à radiação Cerenkov, a qual ocorre devido à passagem de partículas carregadas em um meio com velocidade maior que a velocidade da luz no meio. Por isso, a cada medição, a fibra óptica foi irradiada sem o cintilador acoplado a uma de suas extremidades, para retirar a influência do sinal Cerenkov dos dados. As medidas de caracterização granular, diâmetro interno da cápsula, dose absorvida, taxa de dose absorvida e resolução espacial foram realizadas com feixes de ${ }^{60}$ Co. As medidas de dependência energética foram realizadas com feixes de ${ }^{60} \mathrm{Co},{ }^{137} \mathrm{Cs}$ e raios X de baixa energia. Os sinais (corrente elétrica) detectados diretamente através da irradiação do dosímetro foram integrados no tempo de exposição ao feixe de radiação, uma vez que os valores resultantes de carga elétrica são proporcionais à dose absorvida. Dos resultados pode-se inferir o aumento do sinal com o aumento do tamanho médio 
granular e o aumento do diâmetro interno da cápsula. O dosímetro apresentou independência com a taxa de dose, dependência linear com a dose absorvida e com a energia do feixe de fótons para energias baixas, sendo que para altas energias há um desvio da linearidade. A resolução espacial, embora obtida por três métodos diferentes (função de espalhamento de borda (FEB), função de espalhamento linear (FEL) e função de transferência de modulação (MTF) [14]), apresentou valor de $1,43 \pm 0,07 \mathrm{~mm}$ para o método da $\mathrm{MTF}$, sendo a diferença de $11 \%$ em relação à dimensão do dosímetro a menor encontrada.

Para o melhor compreendimento deste trabalho as noções teóricas são apresentadas no Capítulo 1. A apresentação dos materiais e métodos utilizados para a obtenção dos dados referentes aos objetivos do trabalho estão no Capítulo 2. Os resultados e discussões são apresentados no Capítulo 3 e as conclusões no Capítulo 4. 
1 AsPECTOS TEÓRICOS 


\section{CApÍtulo}

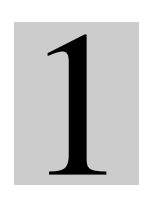

\section{Aspectos Té́RICOS}

A radiação ionizante tem sido aplicada na medicina em diagnóstico e terapia a partir das descobertas dos raios X por Wilhelm Röntgen em 1895 e da radioatividade natural por Antoine Henri Becquerel, Marie e Pierre Curie [15]. Enquanto a radiologia tem a finalidade de diagnosticar o paciente a partir das imagens obtidas com radiação ionizante, a radioterapia tem como objetivo destruir as células tumorais e proteger as células saudáveis. Isto é possível quando a energia da radiação ionizante é absorvida num meio celular podendo anular a capacidade de reprodução das células. Para quantificar a energia absorvida por unidade de massa de um meio absorvedor utiliza-se a grandeza dose absorvida. Uma vez que cada material interage diferentemente com a radiação ionizante, é possível distinguir diferentes patologias na radiologia diagnóstica, assim como cada tipo de câncer pode receber um determinado tratamento radioterápico.

A qualidade dos serviços radioterápicos é regida por protocolos internacionais, nos quais constam que a incerteza total da dose administrada ao paciente não deve ultrapassar 5\% daquela prescrita [3]. Para se obter este controle, testes periódicos são realizados pelos serviços e dentre eles a monitoração da dose liberada pelos equipamentos é necessária para garantir que o paciente está efetivamente recebendo a dose prescrita pelo radioterapeuta. Esse controle é realizado através de dosímetros, que são dispositivos capazes de fornecer um sinal proporcional à dose absorvida em um meio. Na radioterapia diversos tipos de radiação ionizante podem ser utilizados, por exemplo, fótons (raios X e raios gama), elétrons, betas, alfas e nêutrons. Entretanto, a maioria dos tratamentos radioterápicos ocorre através do uso de aceleradores lineares (LINAC) e unidades de cobalto $\left({ }^{60} \mathrm{Co}\right)$. 
Com o aprimoramento dos equipamentos radioterápicos e a evolução das técnicas aplicadas, como radioterapia de intensidade modulada (tratamento realizado com um feixe de fluência não uniforme [16]) e radiocirurgia estereotáxica (tratamento realizado com um aparato estereotáxico e feixes estreitos de radiação distribuídos através de arcos isocêntricos não coplanares [16]), a necessidade de dosímetros com alta resolução espacial e temporal aumentou. Os dosímetros cintiladores tem mostrado resultados significantes quando aplicados ao controle de qualidade de máquinas radioterápicas e à dosimetria de campos pequenos [17], [18], [19]. O antraceno, material cintilador caracterizado como dosímetro neste trabalho, possui vantagens como alta eficiência de cintilação, equivalência à água e tecido mole e possibilidades de medidas in vivo. Como este trabalho envolve feixes de fótons na faixa de energia radioterápica, uma breve introdução sobre interações dessa radiação com a matéria será realizada nesse capítulo.

\subsection{Interações de Fótons com a Matéria}

Quando um feixe de fótons incide em um meio, parte da energia do feixe é refletida, parte é absorvida e uma outra é transferida ao meio. A energia depositada por unidade de massa do meio é denominada dose absorvida. O processo inicial da deposição da energia pode envolver a interação dos fótons do feixe com elétrons do meio, resultando na ejeção desses elétrons dos átomos do material. Ao atravessar o meio, os elétrons ejetados podem provocar outras ionizações e excitações ao longo de seus trajetos. Os principais mecanismos de interação dos raios X e gama com a matéria na área da radioterapia são: efeito fotoelétrico, efeito Compton e produção de pares. A dominância de um efeito ou de outro, em uma dada interação, depende tanto da energia do fóton, $E$, quanto do número atômico do meio absorvedor, Z [2]. A Figura 1.1 apresenta curvas que delimitam as regiões onde os efeitos tem maior probabilidade de ocorrência, para diferentes $Z$ em função de $E$. 


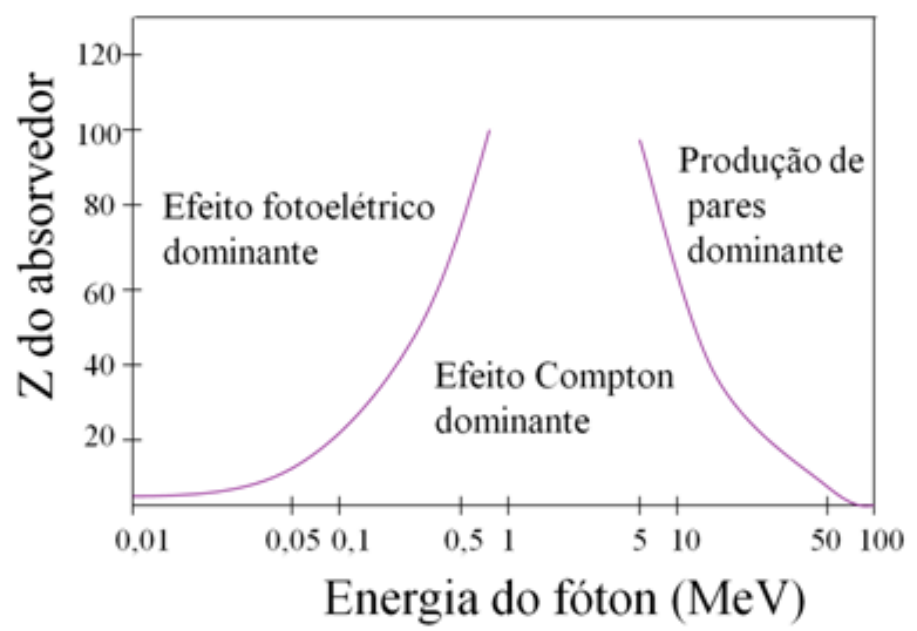

Figura 1.1. Regiões onde os efeitos fotoelétrico, Compton e produção de pares são dominantes em função do número atômico efetivo do material e da energia dos fótons incidentes [1].

Da Figura 1.1 pode-se inferir que o efeito fotoelétrico é dominante para fótons de energias menores, enquanto que o efeito Compton está relacionado com energias médias e altas e a produção de pares às energias altas. Para materiais de baixo número atômico a região de dominância do efeito Compton é grande e diminui conforme $Z$ aumenta. Esses efeitos serão apresentados a seguir.

\section{Efeito Fotoelétrico}

No efeito fotoelétrico elétrons são ejetados dos átomos do meio, devido à absorção de energia dos fótons. Os elétrons ejetados, os fotoelétrons, são originários preferencialmente das camadas mais internas do átomo $(\mathrm{K}, \mathrm{L})$, onde estão fortemente ligados. A energia cinética inicial do fotoelétron $\left(E_{c}\right)$ é dada por:

$$
E_{c}=h \nu-E_{L}
$$

Sendo $h \nu$ a energia total do fóton incidente e $E_{L}$ a energia de ligação do elétron na sua camada.

Uma aproximação da probabilidade de absorção fotoelétrica $(\tau)$ por átomo é dada por: 


$$
\tau \cong C \times \frac{Z^{n}}{E_{\gamma}^{3.5}}
$$

$\mathrm{Na}$ qual o expoente $\mathrm{n}$ pode variar entre 3 e 5 e $C$ é uma constante relativa ao aumento da probabilidade desta interação com o aumento de $Z$ e a diminuição da energia dos fótons [2], [1].

\section{Efeito Compton}

O efeito Compton (ou espalhamento Compton) é caracterizado pela colisão inelástica entre um fóton e um elétron fracamente ligado ao átomo (elétron livre). Nesta interação, o fóton é defletido em um ângulo $\theta$ em relação à direção do fóton incidente, e uma parte da energia deste é cedida ao elétron que é ejetado do átomo. A relação entre a energia transferida do fóton para o elétron e o ângulo de espalhamento do fóton é dada por:

$$
h \nu^{\prime}=\frac{h \nu}{1+\frac{h \nu}{m_{0} c^{2}}(1-\cos \theta)}
$$

Na qual $\mathrm{h} \nu$ é a energia inicial do fóton, $\mathrm{h} \nu^{\prime}$ é a energia do fóton espalhado, $m_{0} c^{2}$ é a energia de repouso do elétron $(0,511 \mathrm{MeV})$ e $\theta$ é o ângulo entre a direção do fóton espalhado e o fóton incidente.

A probabilidade de ocorrer espalhamento Compton $(\sigma)$ por átomo do material depende do número de elétrons disponíveis como objetos espalhadores, i.e., a densidade eletrônica do material [2].

\section{Produção de Pares}

Produção de pares é um processo no qual a energia de um fóton é convertida em um par elétron-pósitron, devido à interação entre o fóton e o campo Coulombiano de um núcleo atômico. A ocorrência da produção de pares tem um limiar de energia igual a 1,02 MeV, ou seja, o dobro da energia de repouso do elétron. Ao percorrer o material, tanto o elétron quanto o pósitron podem interagir com outros átomos, ionizando-os ou excitando-os. O pósitron perderá energia nas possíveis interações 
até ser aniquilado ao se combinar com um dos elétrons livres disponíveis no meio. Desse modo, a interação de pares resulta em dois fótons [20]. A probabilidade de ocorrência da produção de pares $(\pi)$ por núcleo aumenta aproximadamente com $Z^{2}[1]$.

\subsection{Coeficiente de Atenuação Mássico e Coeficiente de Absorção Mássico de Energia}

A atenuação que um feixe de fótons sofre ao atravessar uma espessura $d x$ de material depende do número atômico e da densidade do material. O coeficiente de atenuação linear $\mu$ é definido como a atenuação que o feixe de fótons sofre, por unidade de comprimento de material atravessado e seu valor representa a probabilidade dos fótons serem atenuados. Desse modo, para feixes de fótons utilizados na radioterapia, $\mu$ é a probabilidade de interação dos fótons com átomos do material através dos efeitos fotoelétrico, Compton e produção de pares:

$$
\mu=\tau+\sigma+\pi
$$

A partir do coeficiente de atenuação linear pode-se definir o coeficiente de atenuação mássico dado por $\mu / \rho$, onde $\rho$ é a densidade do material. Se $I_{0}$ é a intensidade do feixe de fótons incidente e $I$ é a intensidade do feixe transmitido através do material, o coeficiente de atenuação mássico pode ser obtido por:

$$
(\mu / \rho)=\frac{1}{x \rho} \ln \left(\frac{I_{0}}{I}\right)
$$

A partir do coeficiente de atenuação mássico pode-se definir o coeficiente de transferência mássico de energia $\mu_{t r}$, que é a fração do coeficiente de atenuação mássico que contribui para a transferência da energia cinética às partículas carregadas, dado por:

$$
\frac{\mu_{t r}}{\rho}=\frac{\mu}{\rho}\left[\frac{E_{k}}{E_{0}}\right]
$$


Na qual $E_{k}$ é uma parcela da energia do feixe convertida em energia cinética do elétron e $E_{0}$ é a energia inicial do fóton.

O coeficiente de absorção mássico de energia $\mu_{e n} / \rho$, para diferentes interações, é uma medida da fração média do coeficiente de transferência de energia que contribui para a absorção de energia pelo material, dado por:

$$
\frac{\mu_{e n}}{\rho}=\frac{\mu_{t r}}{\rho}(1-g)
$$

Na qual $g$ representa a fração média da energia dos elétrons secundários que é perdida em interações radioativas (bremsstrahlung) [21], [22].

\subsection{Dosimetria}

A dosimetria trata da medida da dose absorvida e de outras grandezas ou parâmetros dosimétricos, relevantes radiologicamente, resultantes da interação da radiação ionizante com a matéria num ponto ou volume [1] e o dosímetro é o sensor utilizado para fornecer essas medidas. A grandeza utilizada neste trabalho é a dose absorvida $(D)$, que em qualquer ponto $\mathrm{P}$ num volume $\mathrm{V}$ pode ser definida como:

$$
D=\frac{d \varepsilon}{d m}
$$

Na qual $\varepsilon$ é o valor esperado da energia cedida em um volume finito $V$ durante um intervalo de tempo e $d E$ é a energia cedida a um volume infinitesimal $d V$ com massa $d m$. A unidade da dose absorvida é gray (Gy) sendo que $1 \mathrm{~Gy}=1 \mathrm{~J}^{\mathrm{kg}} \mathrm{g}^{-1}$.

$\mathrm{Na}$ radioterapia a dosimetria é controlada segundo protocolos internacionais como o da Comissão Internacional de Unidades e Medidas de Radiação (ICRU), que garante a qualidade do serviço radioterápico. Segundo o relatório 24 da ICRU [3], a incerteza máxima na dose administrada ao paciente deve ser de $\pm 5 \%$. Apesar da câmara de ionização ser o dosímetro preconizado para ser utilizado no controle de qualidade e dosimetria dos tratamentos radioterápicos, existem diversos tipos de dosímetros que são utilizados como ferramentas adicionais, dentre eles 
dosímetros químicos, termoluminescentes, de estado sólido e outros [1,2,16]. Para um material ser um dosímetro, algumas propriedades devem ser consideradas em sua caracterização, tais como: precisão e acurácia, resolução espacial, estabilidade, linearidade, dependências com a taxa de dose, energia e direção do feixe de radiação.

A precisão ou reprodutibilidade de um dosímetro está relacionada com erros aleatórios devido às flutuações dos parâmetros na instrumentação, condições ambientais e a natureza dos campos de radiação. Pode ser estimada através de medidas repetitivas, sendo que uma precisão alta significa um desvio pequeno entre cada uma delas. A acurácia de um dosímetro expressa a proximidade das medidas ao valor esperado da grandeza que está sendo medida [1].

Idealmente, a resposta de um dosímetro é linearmente proporcional à dose absorvida [15], sendo também aceitável que seja uma função não linear mas unívoca. A Figura 1.2 demonstra dois tipos diferentes de comportamentos da resposta de dosímetros com a dose absorvida. A curva A mostra inicialmente um comportamento linear, depois supralinear e posteriormente a saturação, enquanto a curva B mostra um comportamento linear seguido de saturação, no entanto ambas exibem linearidade em um determinado intervalo de dose.

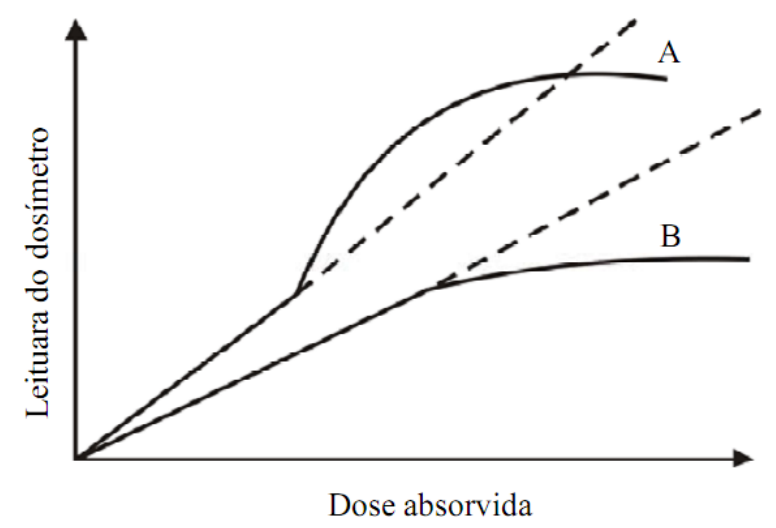

Figura 1.2. Comportamentos diferentes que um dosímetro pode apresentar do sinal em função da dose absorvida. Curva A mostra um comportamento linear, supralinear e saturado. Curva B mostra um comportamento linear e saturado [15].

Os limites inferior e superior de dose podem ser devidos às limitações da instrumentação (ruído de fundo), ou imposto por características do dosímetro que estejam relacionadas com a capacidade de detecção do material detector à menor 
dose absorvida.

Um dosímetro, idealmente, não deve depender da taxa com que a dose está sendo absorvida, da energia e da direção de incidência do feixe de radiação. A uttilização de um dosímetro demanda o conhecimento de suas características para que as medidas sejam realizadas adequadamente. As características encontradas com as calíbrações devem se manter estáveis durante o tempo em que está sendo usado, uma vez que efeitos como temperatura, umidade, luz, entre outros, podem mudar a sensibilidade do dosímetro ou da instrumentação [15]. Com relação à dosimetros cintiladores, a literatura mostra a possível monitoração desses dosímetros através do conhecimento prévio de sua resposta à estimulação com luz ultravioleta, sendo que tal monitoração pode ser realizada durante o uso do dosímetro [23].

\subsection{Cintilação}

O antraceno, material utilizado neste trabalho, é um cristal orgânico cintilador. A cintilação, um tipo de luminescência, é um fenômeno caracterizado pela emissão de luz por um material, devida à absorção da radiação ionizante. Os processos de emissão de luz presentes nesses materiais são fluorescência, fosforescência e fluorescência atrasada. A fluorescência, a principal componente dos materiais orgânicos, ocorre devido às transições na estrutura dos níveis energéticos de uma única molécula, podendo ser observada numa amostra independente de seu estado físico. Por exemplo, a emissão da cintilação no antraceno pode ser observada nos seus estados sólido, em solução ou vapor. Normalmente, a emissão de fótons ocorre com energia menor que a absorvida, devido a processos internos de relaxação não radioativos, como conversão interna e cruzamento entre sistemas [2].

O antraceno, assim como a maioria dos cintiladores orgânicos, devido às propriedades de simetria, possui estrutura eletrônica $\pi$ ilustrada na Figura 1.3. 


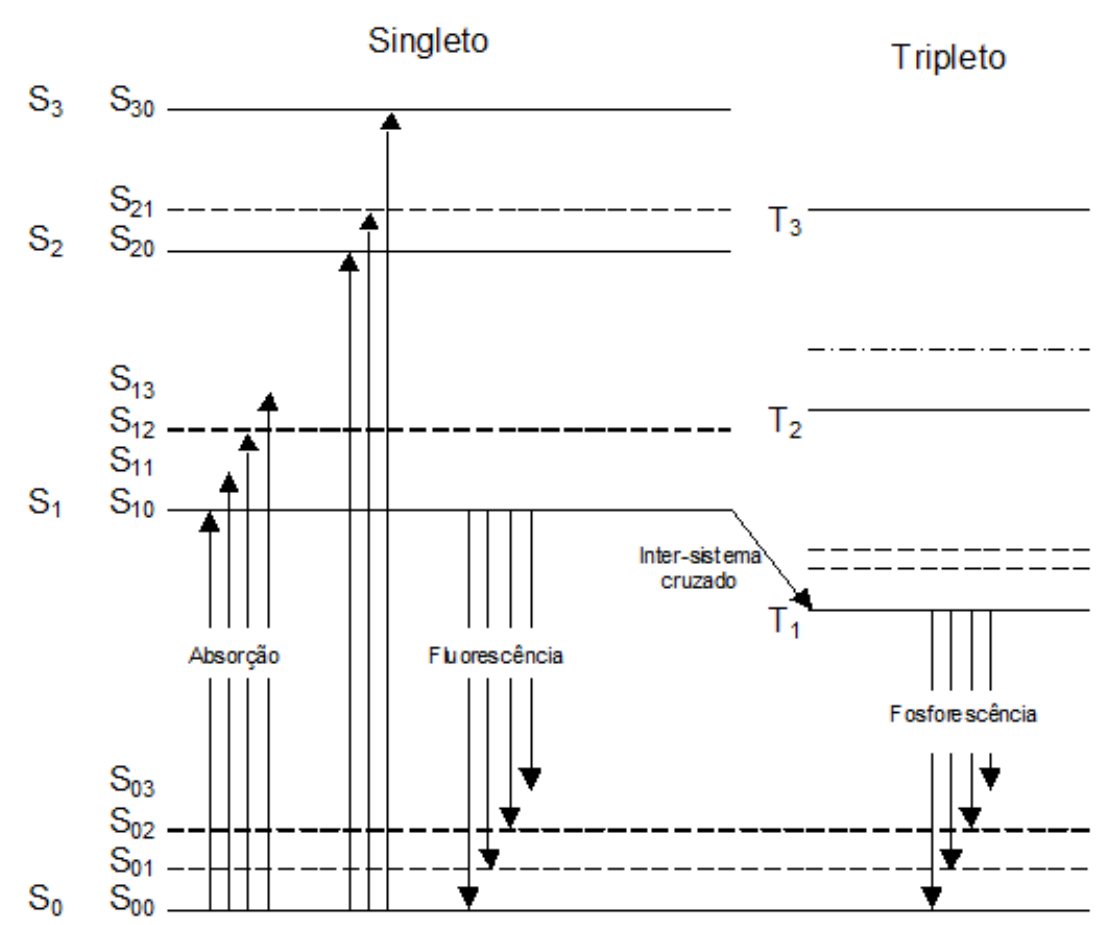

Figura 1.3. Níveis de energia de moléculas orgânicas com estrutura eletrônica $\pi$ [2].

A energia incidente pode ser absorvida pela molécula com a consequente promoção de um elétron para um dos estados mais excitados. Na Figura 1.3, $S_{0}, S_{1}$, $S_{2}, \ldots$ constitui uma série de estados singletos ( spin 0 ), e $T_{1}, T_{2}, T_{3}, \ldots$ constitui uma série de estados tripletos (spin 1). Cada um desses estados é subdividido em uma série de níveis correspondentes aos níveis vibracionais da molécula. Para denotá-los, acrescenta-se um segundo número, por exemplo, o estado $S_{00}$, que representa o estado vibracional de menor energia do estado fundamental. Para cintiladores orgânicos, o intervalo energético entre $S_{0}$ e $S_{1}$ é de 3 ou $4 \mathrm{eV}$, e o intervalo entre os estados vibracionais é de aproximadamente $0,15 \mathrm{eV}$. Como a energia térmica média é em torno de $0,025 \mathrm{eV}$, em temperatura ambiente quase todas as moléculas estão no estado $S_{00}$. Após a absorção de energia, o estado eletrônico singleto excitado de maior energia é desexcitado para o estado singleto $S_{1}$, de menor energia, através de conversões internas não radioativas. A luz fluorescente é emitida em transições entre o estado $S_{10}$ e um dos estados vibracionais do estado fundamental [2].

Considerando que $\tau$ é o tempo de decaimento da fluorescência para o nível $S_{10}$ e $I_{0}$ é a intensidade da luz incidente, a intensidade da fluorescência $(I)$ em um tempo 
$t$ após a excitação será:

$$
I=I_{0} \cdot e^{\frac{-t}{\tau}}
$$

Para a maioria dos cintiladores orgânicos, t é da ordem de nanosegundos.

O tempo de vida no estado tripleto $T_{1}$ é maior que do estado singleto $S_{1}$. Através de uma transição chamada cruzamento entre sistemas, alguns estados singletos excitados podem ser convertidos em estados tripletos. $O$ tempo de vida de $T_{1}$ pode ser da ordem de $10^{-3} s$ para cintiladores orgânicos. A emissão de luz devido à desexcitação do estado $T_{1}$ para $S_{0}$ é chamada de fosforescência. A ocorrência da fosforescência é menos provável que a fluorescência e seu espectro é deslocado para comprimento de ondas maiores que o da fluorescência. Também é possível que algumas moléculas no estado $T_{1}$ sejam novamente excitadas para o estado $S_{1}$, e essas se desexcitarão através de fluorescência conhecida por fluorescência atrasada [2].

A eficiência de cintilação de um material cintilador é definida como a fração de toda a energia das partículas incidentes que é convertida em luz visível. Tal eficiência será tanto menor quanto mais processos não radioativos ocorrerem no cintilador. Algumas das causas essas desexcitações não radioativas estão num grupo chamado quenching, que pode ser provocado, por exemplo, pela presença de impurezas ou danos devido à radiação no material [2]. A diminuição da eficiência da cintilação causada pela passagem de partículas ionizantes são insignificantes em cristais de antraceno [24].

\subsection{Antraceno}

O antraceno, material usado em sua forma cristalina pura como dosímetro nesse trabalho, é um hidrocarboneto aromático policíclico (HPA), com fórmula molecular $C_{14} H_{10}$, obtido através do alcatrão da hulha (carvão mineral constituído por matérias vegetais fossilizadas). Dentre as características deste material estão: densidade $\rho=1,25 \mathrm{~g} / \mathrm{cm}^{3}$; índice de refração $\mathrm{n}=1,62$; número atômico efetivo $Z_{e f}=5,88$; constante de decaimento da fluorescência de 30 ns e comprimento de emissão máxima em 447 nm (Knoll, 1989). A dosimetria é geralmente realizada em água, que possui 
propriedades relacionadas à absorção e espalhamento de radiação próximas às do tecido mole [16]. Para comparaçãp, a densidade e número atômico efetivo da água são, respectivamente: $\rho=1,00 \mathrm{~g} / \mathrm{cm} 3$ e $Z_{e f}=7,4$, além de ambos possuírem valores de elétrons por grama semelhantes.

Nas Figuras 1.4 e 1.5, respectivamente de $\mu / \rho$ e $\mu_{e n} / \rho$ versus energiados fótons, são mostradas as comparações dessas grandezas para o antraceno, acrílico (PMMA), água e tecido mole [25]. A comparação foi realizada para os quatro materiais citados uma vez que o feixe de radiação interage com o acrílico presente no sistema de detecção, e com a água e o tecido mole porque são os meios de interesse na radioterapia. Desse modo, nas figuras os materiais que constituem o dosímetro (antraceno e PMMA), e os de interesse na radioterapia possuem comportamento similares em relação à interação com fótons, o que torna este dosímetro aplicável em radioterapia praticamente sem correções devido às perturbações do feixe no meio.

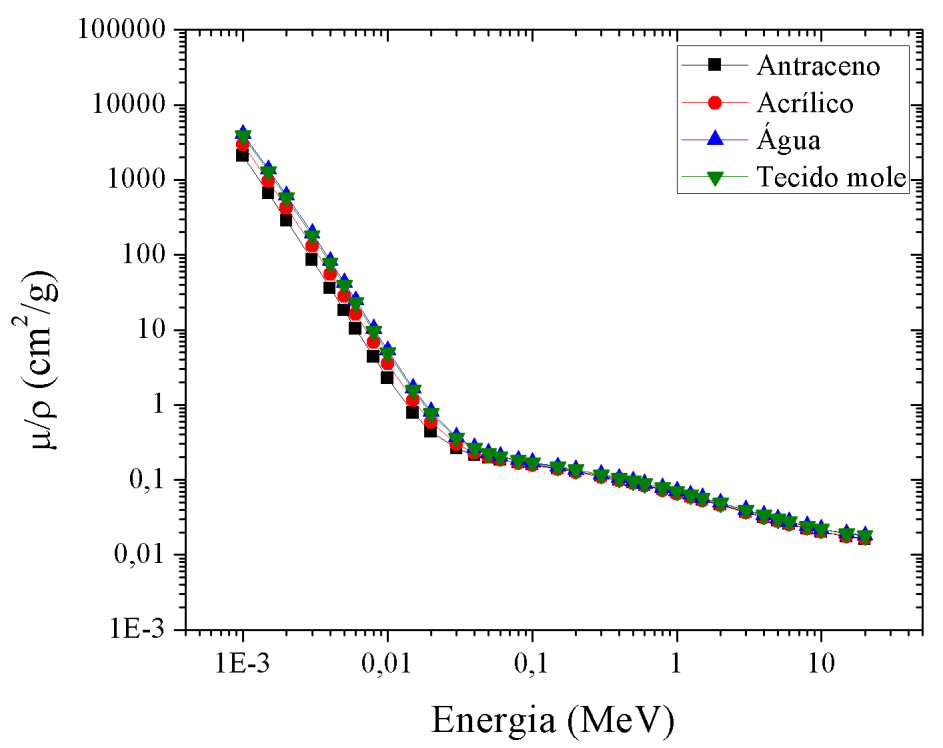

Figura 1.4. Coeficientes de atenuação mássico em função da energia dos fótons para o antraceno, PMMA, água e acrílico. 


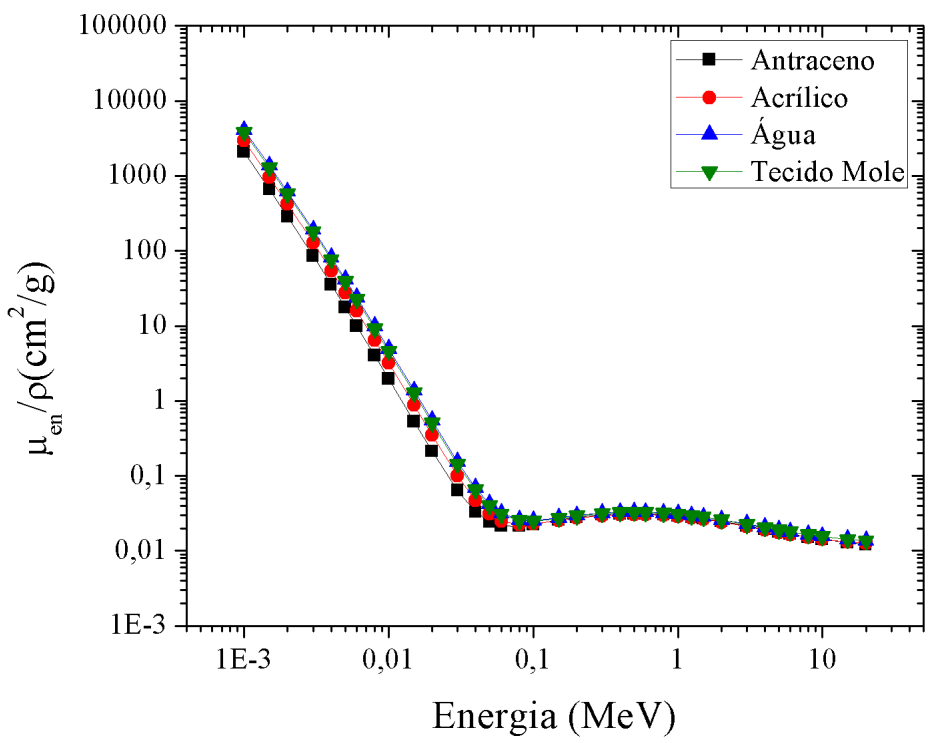

Figura 1.5. Coeficientes de atenuação mássico de energia em função da energia dos fótons para o antraceno, PMMA, água e tecido mole.

Os primeiros trabalhos com o antraceno como detector de radiação começaram a ser publicados na década de 50 [26], [27]. Com relação à eficiência, cristais de antraceno tem eficiência quântica de luminescência próxima a 100\% quando excitados com radiação ultravioleta [24]. Para partículas alfa ou elétrons gerados por efeito Compton a eficiência da cintilação é menor (por exemplo, para elétrons de $5 \mathrm{MeV}$ a eficiência está em torno de $4 \%$ e para partículas alfa de $5 \mathrm{MeV}$ 0,4\%), sendo menor para partículas carregadas mais pesadas [24], [28]. Para fótons de megavoltagem (1,25 MeV), Rubo em 2001 mostrou sua lineridade com a dose absorvida e aplicabilidade na radioterapia [13].

Além de cintiladores plásticos, no qual o antraceno é o cintilador, comercialmente se encontram disponíveis uma variedade de outros dosímetros com diversos tipos de materiais para a matriz plástica, como o polivinil tolueno ou polivinil benzeno, e materiais sendo o componente fluorescente como o 2,5-Diphenyloxazole (PPO) [29].

De maneira geral, tanto os hidrocarbonetos policíclicos aromáticos (HPAs) quanto seus derivados estão associados ao aumento da incidência de diversos tipos de cânceres no homem; embora o antraceno não seja carcinogênico como outros HPAs, ele é considerado tóxico [30], [31]. Portanto requer cuidados quanto ao manuseio, os quais estão descritos no Apêndice A. 


\subsection{Fibras Ópticas}

Uma vez que neste trabalho foram utilizadas fibras ópticas para coletar o sinal do cintilador de antraceno e essas podem influenciar a eficiência dessa coleta, noções sobre fibras ópticas serão apresentadas a seguir. Fibras ópticas são fibras cilíndricas finas, flexíveis e transparentes que tem como objetivo transportar luz entre suas extremidades. As fibras ópticas consistem tipicamente de um núcleo de vidro ou plástico envolto em um revestimento, também constituído de vidro ou plástico, com índice de refração menor que o índice de refração do núcleo. A propagação da luz no núcleo da fibra óptica se deve à reflexão interna total (Figura 1.6) e ocorre quando a luz é totalmente refletida ao passar de um meio com índice de refração maior para um com índice de refração menor. Esse fenômeno é uma consequência da lei de Snell, a qual relaciona a razão entre os senos dos ângulos de incidência e refração (considerando a direção normal perpendicular ao plano de interface entre os meios) inversamente à razão entre os índices de refração.

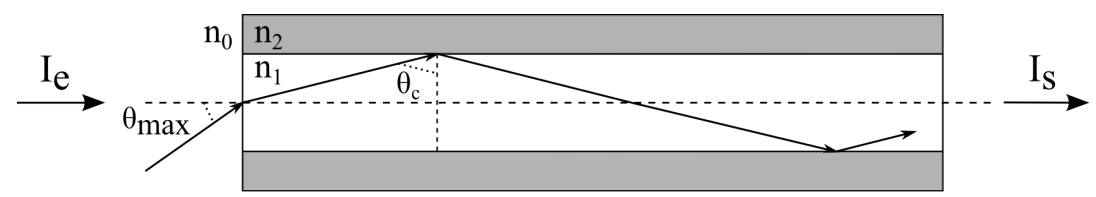

Figura 1.6. Reflexão interna da luz (representada pelas flechas) em uma fibra óptica de índice degrau.

A Figura 1.6 ilustra a propagação da luz dentro de uma fibra óptica, na qual o ângulo crítico $\left(\theta_{c}\right)$ pelo qual a luz pode ser propagada internamente na fibra determina o ângulo máximo em que a radiação pode ser aceita $(\theta)$. Normalmente essa informação está implícita na definição de abertura numérica $(A N)$ :

$$
A N=n_{0} \operatorname{sen} \theta_{\max }
$$

Na qual $\theta$ é o ângulo de incidência mostrado na Figura 1.6. A eficiência da coleta do sinal pela fibra dependerá da abertura numérica e do diâmetro do núcleo. A $A N$ pode ser obtida em função dos índices de refração da fibra e do meio por: 


$$
A N=\sqrt{n_{1}^{2}-n_{2}^{2}}
$$

A atenuação do sinal transportado pela fibra determina qual o comprimento que uma fibra óptica deve ter antes que o sinal coletado na entrada não possa mais ser detectado na saída. Essa perda, medida em decibéis, é definida como dez vezes o logaritmo da razão entre a intensidade do sinal de entrada $I_{e}$ e a intensidade do sinal de saída $I_{s}$ :

$$
a=10 \log \left(\frac{I_{e}}{I_{s}}\right)
$$

Dos diferentes tipos de fibras ópticas disponíveis, essas podem ser classificadas em fibras multimodo e monomodo, de índice degrau e índice gradual. Fibras multimodo permitem a passagem de mais de um sinal, diferente das monomodos que permitem a passagem de apenas um sinal. Além disso, fibras multimodo costumam ter diâmetros maiores que as monomodos. A diferença entre índices degrau e gradual é que as primeiras possuem núcleos com índice de refração constantes enquanto as últimas possuem núcleos compostos por diferentes camadas com índices de refração gradualmente decrescentes a partir do núcleo radialmente.

As fibras multimodos de índice degrau são as mais indicadas para se trabalhar com cintiladores pelo fato delas possuírem diâmetros grandes, o que facilita o acoplamento ao dosímetro, e por terem uma abertura numérica suficiente para uma coleta de sinal eficiente [32], [33].

\subsection{Efeito Cerenkov}

A dosimetria de cintilação tipicamente utiliza uma fibra óptica como guia do sinal do cintilador para um dispositivo de aquisição como uma fotomultiplicadora [1]. O principal efeito da radiação ionizante nas fibras ópticas é a produção de radiação Cerenkov, a qual compromete o sinal do cintilador [34]. Tal radiação foi vastamente documentada por Jelly em 1958 [35], sendo produzida quando uma partícula carregada atravessa um meio, com índice de refração $n$, com velocidade 
maior que a da luz no meio. Ou seja, essa radiação é gerada quando $n \beta$ excede 1 , onde $\beta$ é a razão entre a velocidade da partícula carregada $v$ e a velocidade da luz no vácuo $c$. O ângulo $\theta$ de emissão da radiação em relação à direção de propagação da partícula é dado por:

$$
\theta=\arccos \left(\frac{1}{n \beta}\right)
$$

A distribuição espectral da radiação Cerenkov compreende toda a região do visível, sendo mais intensa na região do azul (400 - $480 \mathrm{~nm}$ ). Um estudo em relação à intensidade da radiação Cerenkov produzida nas fibras ópticas em função das características das fibras pode ser encontrado em [36].

Uma vez que a radiação Cerenkov compromete o sinal do cintildor, elas deve ser removida. A literatura apresenta diversas técnicas para essa finalidade [37], como: análise temporal [38], filtração óptica [39] e subtração [4], [5], [10]. Neste trabalho a técnica da subtração foi utiliada, que consiste na irradiação de duas fibras ópticas, uma com o cintilador acoplado e a outra sem (sinal de referência), de modo que o sinal obtido pela fibra de referência seja subtraído do sinal do cintilador. Esse método é recomendado quando as emissões do cintilador e da radiação Cerenkov tiverem seus comprimentos de onda e suas constantes de decaimento próximos. 
2 Materiais e Métodos 


\section{Capítulo}

\section{MATERIAIS E MÉTOdos}

\subsection{Materiais}

- Antraceno obtido comercialmente da marca Dinâmica com 99\% de pureza. Este material apresenta emissão máxima em $447 \mathrm{~nm}$, densidade $\rho=1,25 \mathrm{~g} / \mathrm{cm}^{3}$, número atômico efetivo $Z_{e f}=5,88$ e tempo de decaimento da cintilação de $30 \mathrm{~ns}$,

- Fibras ópticas multímodo com índice degrau Mitsubishi Rayon Co./ESKA/CK-40. Núcleo de acrílico de $980 \mu m$, indice de refração de 1,49 e abertura numérica de 0,5 . Transmite ao longo de todo o espectro na região visível, com uma perda de transmissão de aproximadamente $200 \mathrm{~dB} / \mathrm{km}$ em $400 \mathrm{~nm}$,

- Fotomultiplicadora Electron Tubes Limited/9829A/32111, com resposta espectral entre 300 e $650 \mathrm{~nm}$, diâmetro ativo do tubo de $46 \mathrm{~mm}$, sequência de 12 dinodos, voltagem mínima e máxima de 1600 e 1900 V respectivamente, ganho de $6,0 \times 10^{6}$ e ruído de fundo típico de $3 \times 10^{-9} \mathrm{~A}$,

- Eletrômeto Keithley/610C,

- Fonte de alta tensão,

- Fonte de ${ }^{60} \mathrm{Co}$ Theratronix/Theratron/780C calibrada com câmara de ionização FARMER/0,6cc e eletrômetro CNMC/11 e fonte de ${ }^{137} \mathrm{Cs}$.

- Raios X de Ortovoltagem/Philips/RT-250. 


\subsection{Métodos}

O sistema de irradiação do dosímetro de antraceno, detecção e leitura do sinal foram montados conforme ilustrado na Figura 2.1. Uma vez que as medidas realizadas foram de caracterização do dosímetro, os experimentos foram realizados no ar, a uma distância foco-superfície (DFS) (ou distância foco-dosímetro, DFD) de $80 \mathrm{~cm}$ e sob irradiação de um campo $10 \times 10 \mathrm{~cm}^{2}$ calibrado de feixes do ${ }^{60} \mathrm{Co}$. O dosímetro foi acoplado a uma fibra óptica, cuja função foi transportar o sinal para uma fotomultiplicadora localizada fora da sala de irradiação. As leituras em corrente dos sinais do cintilador foram obtidas através de um amperímetro conectado à saída de um eletrômetro. Os dados armazenados foram integrados no tempo para assim se obter os valores de carga, já que esses são proporcionais à energia absorvida pelo cintilador. Para descontar o sinal Cerenkov (fibra de referência), o mesmo arranjo experimental foi utilizado, irradiando-se o sistema sem o cintilador acoplado à fibra, sendo esse sinal subtraído do sinal coletado com o cintilador.

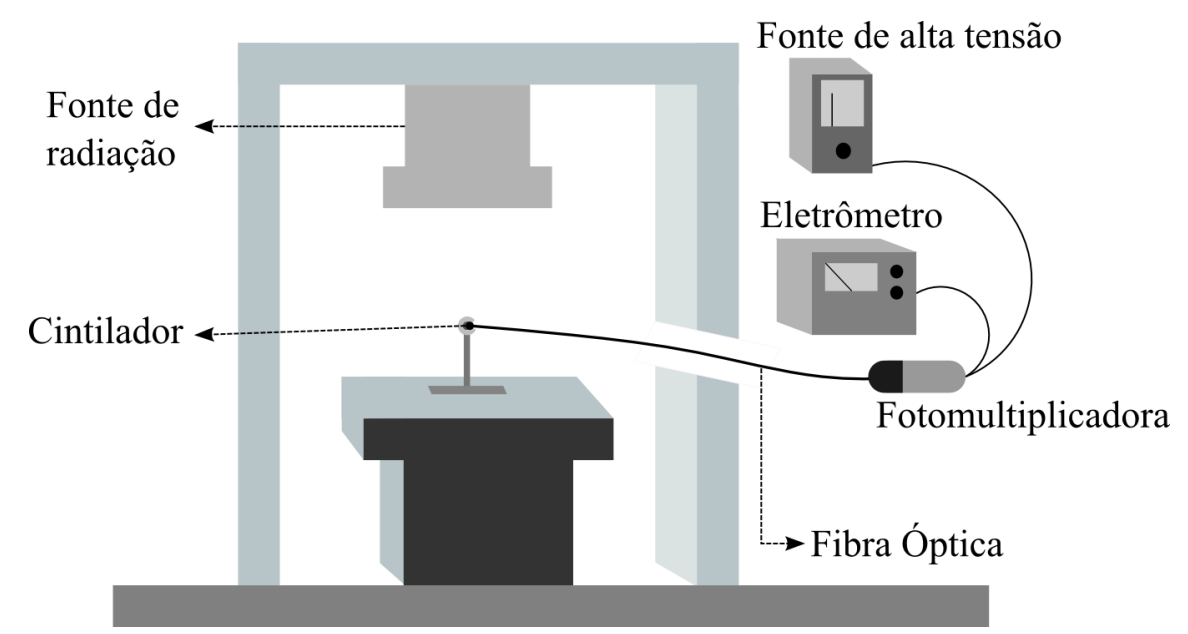

Figura 2.1. Esquema da irradiação do dosímetro de antraceno com sistema de detecção e leitura do sinal. A radiação detectada é transportada pela fibra óptica para uma fotomultiplicadora alimentada por uma fonte de alta tensão. As leituras são realizadas por um multímetro conectado na saída do eletrômetro. 
As incertezas das medidas $\sigma$ foram calculadas através dos desvios padrões $\sigma_{d}$ de aproximadamente 30 dados coletados por medida e da incerteza do amperímetro de $0,1 \mu \mathrm{A}$ :

$$
\sigma=\sqrt{\sigma_{d}^{2}+0,1^{2}}
$$

\section{Verificação do Sistema Eletrônico}

Um amperímetro foi acoplado à saída do eletrômetro devido à flutuação natural do sistema eletrônico em razão dos seus componentes e da rede elétrica local, juntamente com a dificuldade em ler o sinal através do visor do eletrômetro analógico. Para verificar a relação entre o sinal do eletrômetro e o sinal no multímetro, utilizou-se um sistema elétrico simples baseado em um resistor variável conectado em série com uma pilha. Desse modo, uma curva de calibração pode ser obtida a partir de correntes conhecidas. As mudanças das escalas no eletrômetro também foram verificadas, para averiguar a reprodutibilidade do sinal nas várias possíveis escalas (de $10^{-5} A$ à $10^{-9} A$ ) a serem usadas no trabalho.

\section{Detecção da Cintilação}

Uma maneira de otimizar o desempenho de um dosímetro cintilador é aumentar a eficiência da coleta da sua luz nas interfaces do sistema de deteç̧ão. Para tal, uma dessas interfaces é o acoplamento do dosímetro com a fibra óptica (Figura 2.2).

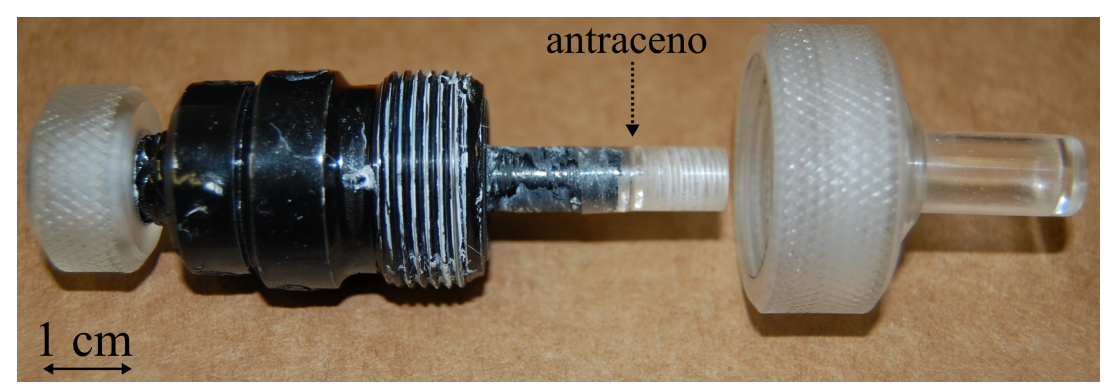

Figura 2.2. Suporte de acrílico (em preto) que permite alinhar a fibra óptica com a cápsula do antraceno (indicada pela flecha tracejada). 
As extremidades das fibras ópticas foram polidas com lixas de água, uma vez que a ausência de polimento das extremidades reduz a coleta da luz em aproximadamente $40 \%$ [40].

Para evitar influência indesejada de outras fontes luminosas, a fibra óptica foi encapada com tubo termoretrátil preto. A foto multiplicadora foi apropriadamente vedada com uma capa de chumbo e papel alumínio, tanto para evitar possíveis influências externas de campos magnéticos como da entrada de luz além da proveniente do cintilador.

\section{Relação Sinal-Ruído}

Uma outra maneira de aumentar a eficiência da detecção da luz do cintilador é considerar a relação sinal/ruído $(S / R)$. A relação sinal-ruído foi obtida, considerando as mesmas condições ambientais, para quatro tensões diferentes aplicadas na fotomultiplicadora (1600, 1700, 1800 e $1900 \mathrm{~V})$, respeitando seu limites de funcionamento (1600-1900 V), para verificar qual a melhor tensão a ser utilizada em todos os experimento com a melhor relação sinal-ruído possível. O ruído foi obtido, sem irradiação, através da corrente detectada com o sistema disposto conforme a Figura 2.1. O sinal foi adquirido irradiando-se no ar o dosimetro de antraceno por $30 \mathrm{~s}$, com o feixe do ${ }^{60} \mathrm{Co}$, num campo $10 \mathrm{x} 10 \mathrm{~cm}^{2}$ e DFD de 80 $\mathrm{cm}$. Para todos os dados obtidos, tanto o ruído quanto o sinal, as incertezas foram calculadas segundo a Equação 2.1. A granulosidade do cintilador utilizada foi escolhida como a menor possível e os grânulos foram encapsulados em um cilindro com $1 \mathrm{~mm}$ de diâmetro e 1,2 mm, de comprimento de acordo com o trabalho de Rubo [13].

\section{Dependência do Sinal do Cintilador com a Granulosidade}

O antraceno em sua forma cristalina pura foi utilizado anteriormente por outros autores como detector de radiação. Rubo em 2001 mostrou sua viabilidade como um dosímetro, assim, a avaliação granulométrica do sinal é importante para a otimização da sua resposta. A granulometria, ou análise granulométrica, é o processo no qual se objetiva determinar ou separar, dentro de faixas pré-estabelecidas de tamanhos, os grânulos de uma amostra. Diversos métodos podem ser aplicados [41], a escolha 
de um ou outro método depende do tipo de amostra usada, como o método da peneiração, o qual foi utilizado nesse trabalho.

Para realizar a análise do sinal em função do tamanho dos grânulos de antraceno, esses foram separados por peneiras granulométricas Telastem Peneiras para Análise LTDA/Granutest. As peneiras possuem os seguintes diâmetros de abertura: 0,08; 0,$106 ; 0,125 ; 0,15 ; 0,18$ e $0,42 \mathrm{~mm}$. Arranjando as peneiras em ordem decrescente de tamanho de abertura, as amostras de antraceno foram coletadas, cada uma correspondendo a um dado intervalo de tamanho, conforme a Figura 2.3. Cada amostra foi colocada em uma cápsula cilíndrica, com interior de $1 \mathrm{~mm}$ de diâmetro e 1,2 $\mathrm{mm}$ de comprimento, e irradiada durante $30 \mathrm{~s}$, sendo o sinal adquirido integrado nesse tempo. Desse modo foram obtidas cinco amostras para se avaliar a dependência do sinal com a granulosidade média.

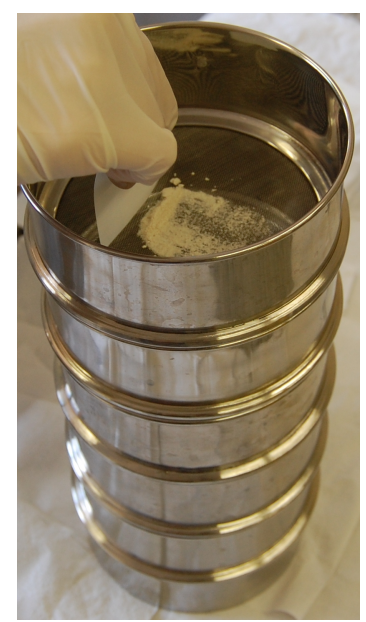

Figura 2.3. Peneiras granulométricas utilizadas para a separação dos grânulos de antraceno.

\section{Dependência do Sinal do Cintilador com o Diâmetro Interno da Cápsula}

Após a avaliação do sinal em função da granulosidade, escolheu-se o tamanho do grânulo que apresentou a maior resposta em função da dose absorvida. A análise foi realizada mantendo o comprimento de 1,2 $\mathrm{mm}$ da cápsula cilíndrica de antraceno, com diâmetros internos de: 0,$8 ; 1,0 ; 1,2 ; 1,3 ; 1,4$ e $1,6 \mathrm{~mm}$. Dos resultados obtidos, o diâmetro da cápsula de antraceno para o qual foi obtido o maior sinal foi escolhido para as demais medidas de caracterização. 


\section{Dependência do Sinal do Cintilador com a Dose Absorvida}

Para se obter o valor de sinal, proporcional à dose absorvida pelo dosímetro de antraceno, foi necessário integrar o valor da corrente obtido pela conexão multímetro-eletrômetro, no tempo em que o dosímetro foi irradiado. Deste modo obteve-se a dependência do sinal em função da dose absorvida no intervalo de 0,03 a 2 Gy.

\section{Dependência do Sinal do Cintilador com a Taxa de Dose Absorvida}

A dependência do sinal do dosímetro com a taxa de dose foi verificada irradiando-se o cintilador à DFDs de 80, 160, 240, 320 e $400 \mathrm{~cm}$. Para as análises , a correção com o inverso do quadrado da distância foi realizada para que a dependência com a taxa de dose fosse o único parâmetro analisado.

\section{Dependência Energética do Sinal do Cintilador}

A dependência do sinal com a energia do feixe de fótons do dosímetro de antraceno foi analisada irradiando-o com fótons do ${ }^{60} \mathrm{Co}(1,25 \mathrm{MeV}),{ }^{137} \mathrm{Cs}(0,662$ $\mathrm{MeV}$ ) e raios $\mathrm{X}$. Para o cálculo da energia dos raios $\mathrm{X}$ considerou-se que, numa aproximação, a energia efetiva de um feixe polienergético de raios $\mathrm{X}$ é àquela equivalente a de um feixe monoenergético, com o mesmo valor de camada semiredutora. A camada semiredutora é a espessura de um determinado material que atenua a intensidade de um feixe de radiação pela metade.

Da lei de Lambert-Beer tem-se:

$$
I=I_{0} e^{-\mu x}
$$

sendo $I$ e $I_{0}$ as intensidades dos feixes antes e depois de atravessar o material, enquanto que $x$ e $\mu$ são a espessura do material e o coeficiente de atenuação linear, respectivamente. Deste modo, se $x_{1 / 2}$ é a espessura de um dado material pela qual tem-se $I=I_{0} / 2$, então:

$$
\frac{I_{0}}{2}=I_{0} e^{-\mu x_{1 / 2}}
$$




$$
\mu=\frac{0,693}{x_{1 / 2}}
$$

Assim, a partir do valor do coeficiente de atenuação de um dado material, que é dependente da energia do feixe de radiação, é possível obter-se a energia efetiva de um feixe polienergético interpolando-se o valor de $\mu$ encontrado, utilizando dados tabelados em referências [25].

\section{Resolução Espacial do Dosímetro}

A resolução espacial do dosímetro de antraceno foi obtida através de três métodos relacionados e equivalentes: função de espalhamento de borda (FEB), função de espalhamento linear (FEL) e função de transferência de modulação (MTF). O método MTF relaciona a magnitude (contraste) do sinal de um sistema de detecção com a frequência espacial relativa às frequências baixas [14]. Este conceito pode ser melhor compreendido considerando-se várias imagens com diferentes padrões de frequências espaciais (Figura 2.4).

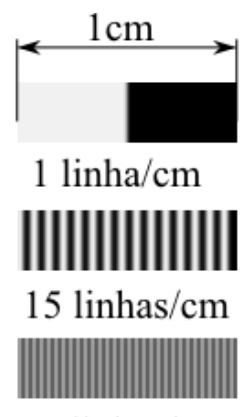

32 linhas/cm

Figura 2.4. Imagens com frequência de linhas por comprimento diferentes, mostrando que para um determinado detector, quanto maior a frequência menor o contraste da imagem.

Pela definição de modulação $M$ (contraste):

$$
M=\frac{I_{\max }-I_{\min }}{I_{\max }+I_{\min }}
$$

da qual $I_{\max }$ e $I_{\min }$ são as intensidades máxima e mínima da imagem. Da Figura 2.4 
é possível inferir que, para um determinado detector, conforme a frequência das linhas aumenta, o contraste diminui, até um limite em que não é mais possível resolver os padrões das linhas.

Matematicamente, a MTF é definida como a transformada de Fourier da (FEL) [14]. No caso desse trabalho, a FEL seria o perfil de campo, obtido com o dosímetro de antraceno, de um feixe de radiação ao passar por uma fenda estreita o suficiente para ser aproximada a uma fenda infinitesimal (Figura 2.5).

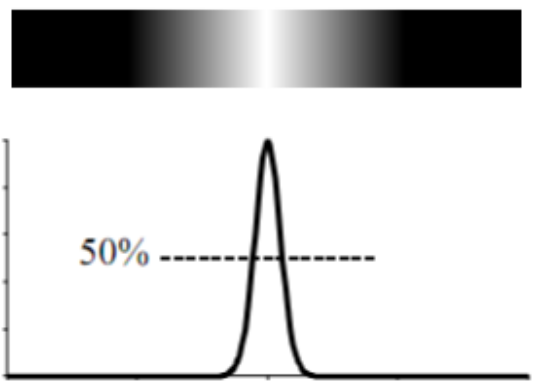

Figura 2.5. Resposta de um sistema a uma fenda praticamente infinitesimal.

A FEL está relacionada com a FEB pela expressão [14]:

$$
F E L(x)=\frac{\partial F E B(x)}{\partial x}
$$

Por sua vez, neste trabalho a FEB foi obtida medindo-se o sinal do detector no eixo central de um feixe do ${ }^{60} \mathrm{Co}$, com a metade do campo blindada por $5 \mathrm{~cm}$ de chumbo (Figura 2.6). A distância percorrida pelo dosímetro em cada medida (passo) foi de $0,5 \mathrm{~mm}$, sendo que a granulosidade e cápsula interna do dosímetro de antraceno possuíam dimensões obtidas dos respectivos experimentos realizados. 


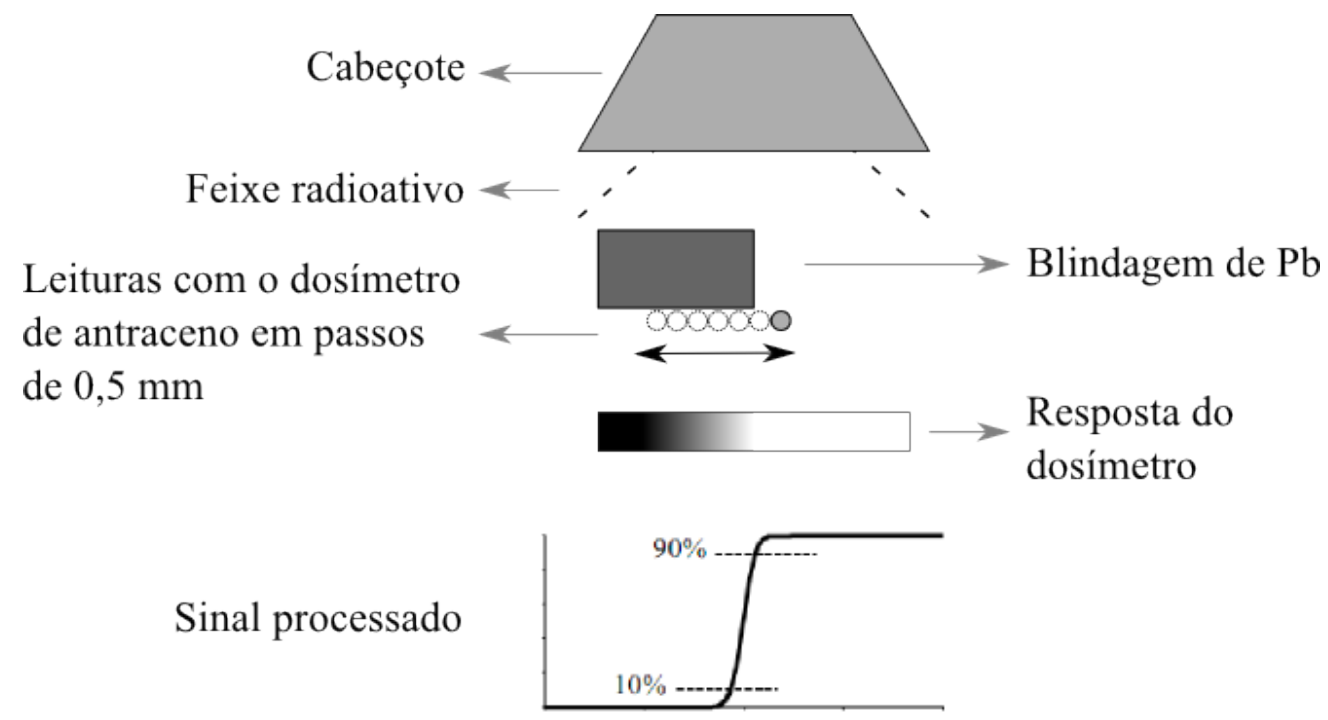

Figura 2.6. Esquema do sistema de irradiação do dosímetro de antraceno para obtenção do perfil de borda.

O método da MTF é baseado no fato de que, para um detector ideal, em uma descontinuidade, a resposta obtida seria uma função degrau. Essa função degrau pode ser modelada como a soma de senóides com frequências de $-\infty$ à $+\infty$ (Figura 2.7)

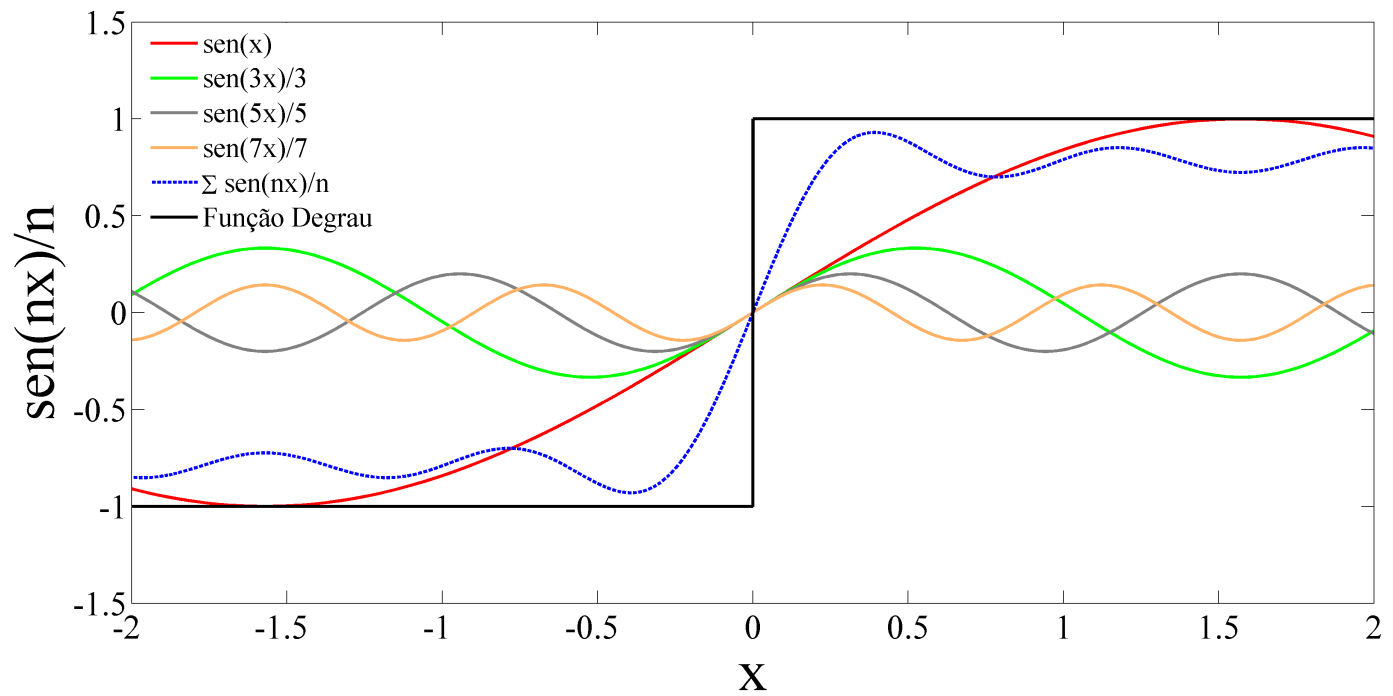

Figura 2.7. Resposta de um detector ideal a uma descontinuidade, que pode ser modelada como a somatória de senóides com frequência de $-\infty$ a $+\infty$.

A partir do perfil obtido na descontinuidade, calculou-se a primeira derivada 
da amplitude do sinal em função da distância. Deste modo, adquiriu-se a resposta do dosímetro correspondente ao perfil que se obteria de uma fenda fina em uma blindagem (Figura 2.5). Desses dois perfis (borda e fenda) é possível adquirir o valor de resolução espacial. No caso da borda, obtem-se a distância para a qual o sinal cai de $90 \%$ à $10 \%$ do valor fora da blindagem. Já no caso da fenda, obtém-se o valor da largura à meia altura do perfil. Na MTF a resolução espacial foi obtida através da frequência relativa à magnitude de 10\%, para ser possível a comparação com os outros métodos empregados [14]. 
3 Resultados e Discussões 


\section{CAPÍTUlo}

\section{Resultados E Discussões}

\subsection{Verificação do Sistema Eletrônico}

\section{Relação Eletrômetro-Multímetro}

Para verificar a relação entre os dados lidos no eletrômetro e os dados lidos no multímetro (Figura 3.1), para cada escala do eletrômetro, medidas de correntes conhecidas foram realizadas. A normalização do sinal na saída do eletrômetro, detectado pelo multímetro, mostrou-se independente da escala do sinal no eletrômetro. Deste modo, pela maior facilidade de utilização, optou-se por utilizar o multímetro para exibição dos dados.

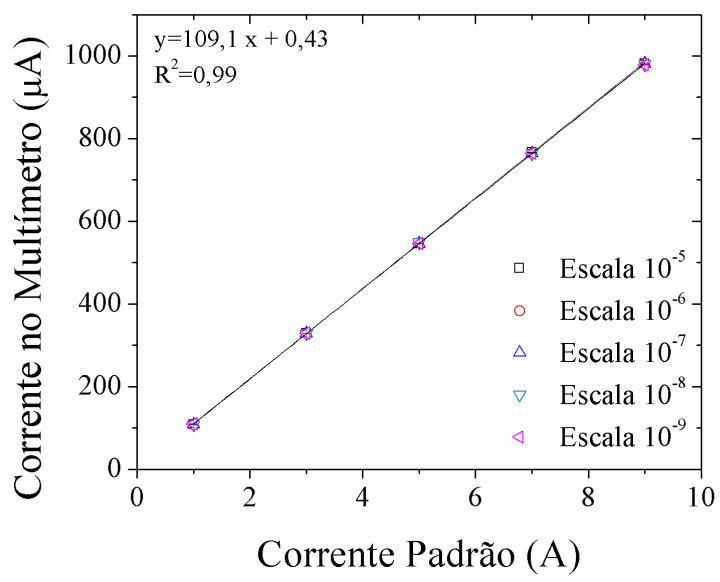

Figura 3.1. Relação entre o sinal conhecido de um sistema elétrico simples, lido diretamento no eletrômetro, e o detectado pelo multímetro conetado na saída do eletrômetro. 


\section{Relação Sinal-Ruído}

A tensão utilizada para alimentar a fotomultiplicadora foi escolhida com base na melhor relação sinal-ruído obtida. O sinal foi adquirido irradiando-se o cintilador de antraceno por $30 \mathrm{~s}$, com grãos macerados e comprimidos numa capsula cilíndrica de $1 \mathrm{~mm}$ de diâmetro e 1,2 $\mathrm{mm}$ de comprimento. O ruído obtido pelo cintilador posicionado segundo a Figura 2.1, pode ter detectado, além da radiação de fuga do irradiador, ruídos da rede elétrica local e do equipamento eletrônico de detecção. Pelas relações encontradas (Tabela 3.1) foi possível averiguar que utilizando a tensão de $1700 \mathrm{~V}$ para alimentar a fotomultiplicadora a melhor razão sinal-ruído foi obtida.

Tabela 3.1. Relação Sinal/Ruído em função das tensões aplicadas na fotomultiplicadora.

\begin{tabular}{cc}
\hline Tensão & Sinal/Ruído \\
\hline \hline $1600 \mathrm{~V}$ & $22,4 \pm 0,7$ \\
$1700 \mathrm{~V}$ & $24,3 \pm 0,7$ \\
$1800 \mathrm{~V}$ & $22,9 \pm 1,3$ \\
$1900 \mathrm{~V}$ & $22,0 \pm 1,2$ \\
\hline
\end{tabular}

\subsection{Caracterização do Dosímetro de Antraceno}

Dependência do Sinal do Cintilador com a Granulosidade

O comportamento do sinal do antraceno em função do seu tamanho granular (Figura 3.2) foi obtido irradiando-se amostras com granulosidades diferentes. Uma vez que as diferentes amostras de antraceno foram adquiridas através de peneiras granulométricas, para verificar a dependência do sinal os valores médios de abertura das peneiras foram de: 0,3;0,165; 0,116;0,093 e 0,04 mm. A Figura 3.2 mostra o aumento do sinal detectado pelo cintilador em função do valor médio de abertura das peneiras granulométricas. 


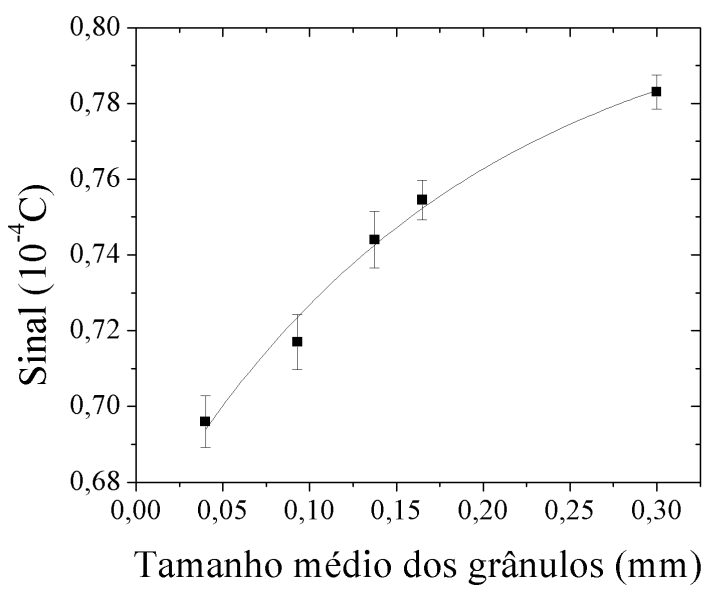

Figura 3.2. Comportamento do sinal do antraceno em função da dimensão média dos grânulos.

A diminuição do sinal com a diminuição do tamanho dos grânulos possivelmente ocorre devido à maior quantidade de interfaces grânulo-ar presentes na amostra, i.e., superfícies onde pode ocorrer espalhamento da luz emitida, resultando numa luz menos intensa coletada pela fibra óptica. Assim, para as demais medidas de caracterização do dosímetro de antraceno, a granulosidade média de 0,30 mm foi escolhida uma vez que apresentou maior sinal.

\section{Dependência do Sinal do Cintilador com o Diâmetro Interno da Cápsula}

A relação entre o sinal recebido do dosímetro de antraceno e o diâmetro da sua cápsula (Figura 3.3) foi averiguada irradiando-se, por 30 s, o dosímetro com granulosidade média de $0,30 \mathrm{~mm}$. O cintilador foi encapsulado em cilindros com 1,2 mm de comprimento e diâmetros de: 0,$8 ; 1,0 ; 1,2 ; 1,3 ; 1,4$ e 1,6 mm.

Dos resultados das irradiações verificou-se o aumento do sinal do cintilador de antraceno com o aumento do diâmetro $(d)$ da sua cápsula (Figura 3.3), numa dependência com $d^{3}$, até possivelmente atingir um regime de saturação. Este comportamento pode ser melhor compreendido analisando-se o cone de aceitação da fibra óptica (Figura 3.4), determinado através da abertura numérica de 0,5 da fibra óptica utilizada. 


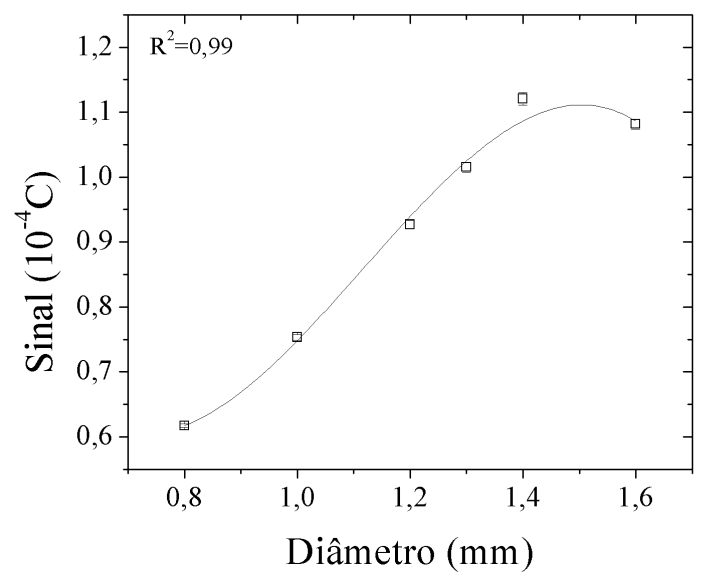

Figura 3.3. Comportamento do sinal do antraceno em função dos diâmetros internos de suas cápsulas.

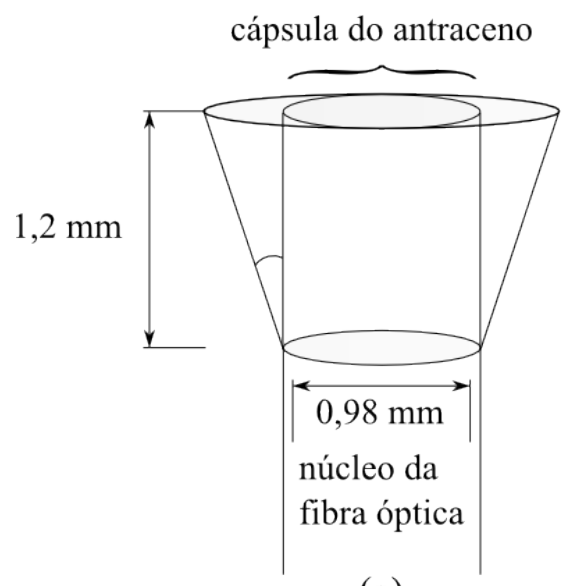

(a)

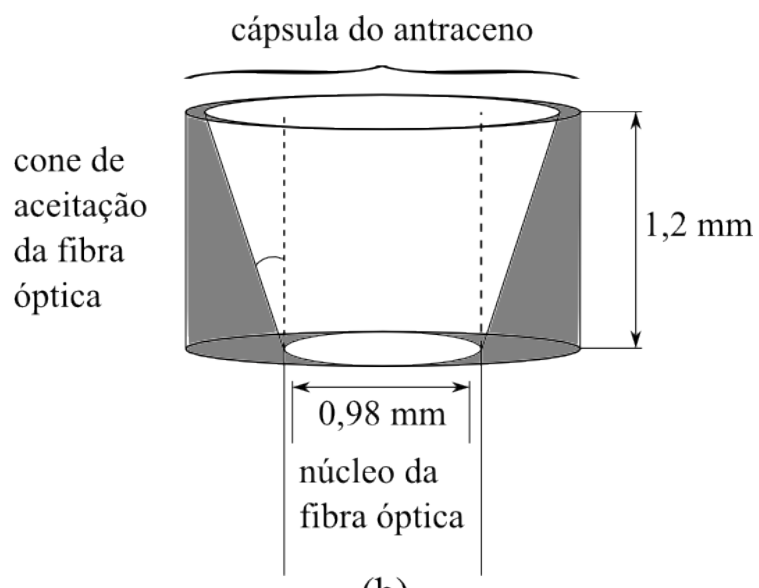

(b)

Figura 3.4. Cone de aceitação da fibra óptica utilizada com abertura numérica de 0,5.(a) cápsula do dosímetro com diâmetro dentro do cone de aceitação e (b) com diâmetro maior que o cone de aceitação.

Como o volume de antraceno dentro do cone de aceitação da fibra óptica aumenta proporcionalmente a $d^{3}$, o sinal possui o mesmo comportamento. Entretanto, há um limite determinado pela fibra óptica (abertura numérica), o qual se ultrapassado, os fótons gerados fora desse cone de aceitação (área cinza na Figura 3.4 não podem ser transportados pela fibra. A amostra utilizada para a realização das demais medidas de caracterização do dosímetro foi aquela inserida na cápsula de 1,6 mm de diâmetro interno. 
Dependência do Sinal do Cintilador com a Dose Absorvida

A relação do sinal obtido com a dose absorvida foi adquirida utilizando o feixe calibrado do ${ }^{60} \mathrm{Co}$ (Figura 3.5).

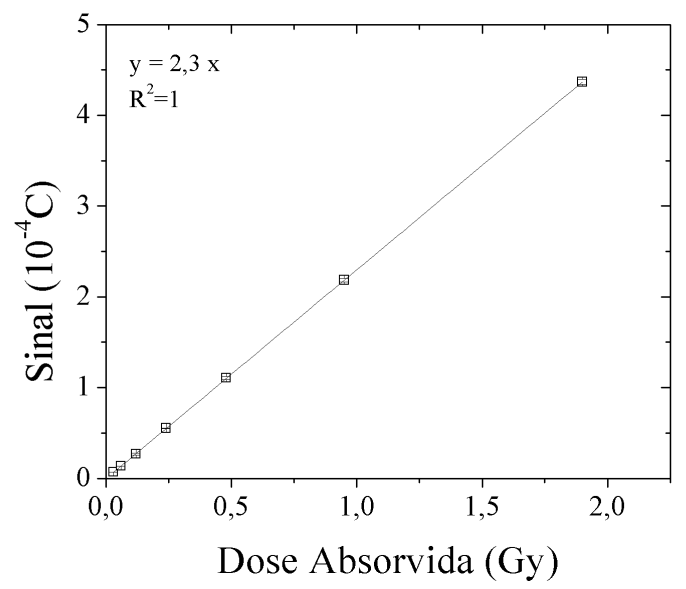

Figura 3.5. Dependência do sinal do cintilador com a dose absorvida para feixes calibrados do ${ }^{60} \mathrm{Co}$.

A resposta linear apresentada na Figura 3.5 possui limite inferior dependente do equipamento utilizado para irradiação e da eletrônica da detecção da cintilação. A fonte de ${ }^{60}$ Co tem um tempo de trânsito para irradiação (entrada e saída) de $0,5 \mathrm{~s}$, enquanto que o multímetro afere uma medida a cada 1 s no mínimo. Rubo mostrou que para doses maiores que as utilizadas em radioterapia o sinal do cintilador de antraceno se mantém linear com a dose absorvida [13].

Dependência do Sinal do Cintilador com a Taxa de Dose Absorvida

A dependência do sinal do cintilador com a taxa de dose (Figura 3.6) foi verificada irradiando-o por $30 \mathrm{~s}$ a diferentes DFDs da fonte de ${ }^{60} \mathrm{Co}$. Na Figura 3.6 o sinal dado em coulombs foi multiplicado pelo quadrado da distância para torná-lo independente deste parâmetro. 


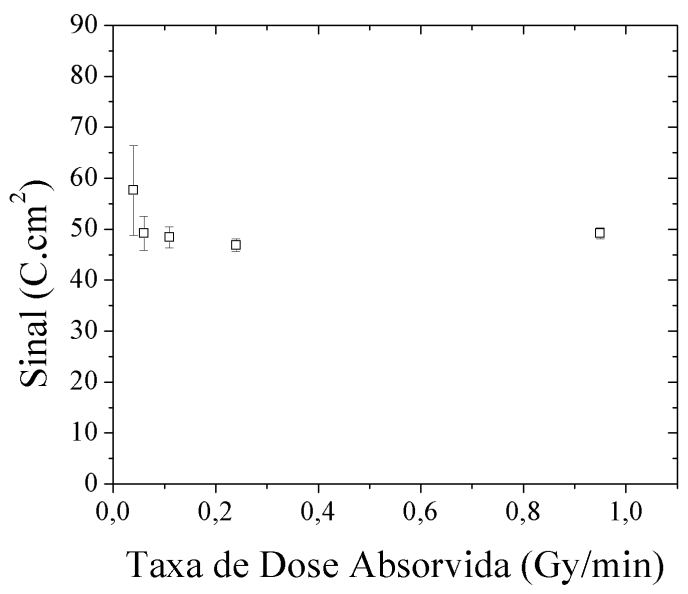

Figura 3.6. Dependência do sinal do cintilador com a taxa de dose absorvida, independente do quadrado da distância (foco-superfície) da fonte de ${ }^{60} \mathrm{Co}$.

O comportamento do sinal obtido na irradiação do antraceno mostrou praticamente não depender da taxa de dose, como encontrado na literatura para outros dosímetros cintiladores [42]. Para a taxa de dose de 0,04 Gy/min, o sinal obtido apresentou uma incerteza maior em relação aos outros dados, possivelmente devida à maior flutuação dos dispositivos eletrônicos com relação à intensidade menor de radiação recebida pelo detector.

\section{Dependência Energética do Sinal do Cintilador}

A dependência do sinal do dosímetro cintilador com a energia do feixe de fótons (Figura 3.7) foi analisada através da irradiação do detector com fontes de ${ }^{60} \mathrm{Co}$, ${ }^{137}$ Cs e raios X. Para os feixes de raios X polienergéticos a energia efetiva foi calculada segundo a metodologia apresentada no Capítulo 2. 


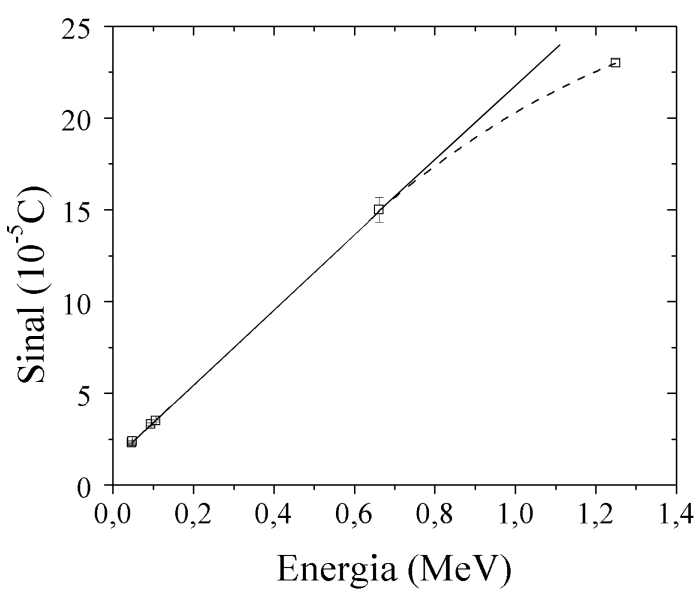

Figura 3.7. Dependência do sinal do dosímetro cintilador com a energia do feixe de fótons.

Dos resultados da Figura 3.7 observa-se que o valor do sinal é menor para energias menores e aumenta linearmente à medida que a energia do feixe aumenta. Para valores maiores de energia do feixe há um desvio da linearidade, tendendo a um valor constante do sinal. A sensibilidade obtida com o antraceno, para energias menores, permite que esse dosímetro possa ser aplicado em outras áreas além da radioterapia como, por exemplo, em radiodiagnóstico.

\section{Resolução Espacial do Dosímetro}

A resposta do dosímetro de antraceno ao medir uma região de descontinuidade foi utilizada para avaliar sua resolução espacial, segundo as metodologias apresentadas no Capítulo 2. A descontinuidade foi medida através da borda de uma blindagem de chumbo de $5 \mathrm{~cm}$ de espessura, posicionada no centro do campo de um feixe de radiação do ${ }^{60} \mathrm{Co}$. O perfil obtido (Figura 3.8) mostra a diminuição do sinal ao entrar na região blindada, com passos de $0,5 \mathrm{~mm}$. 


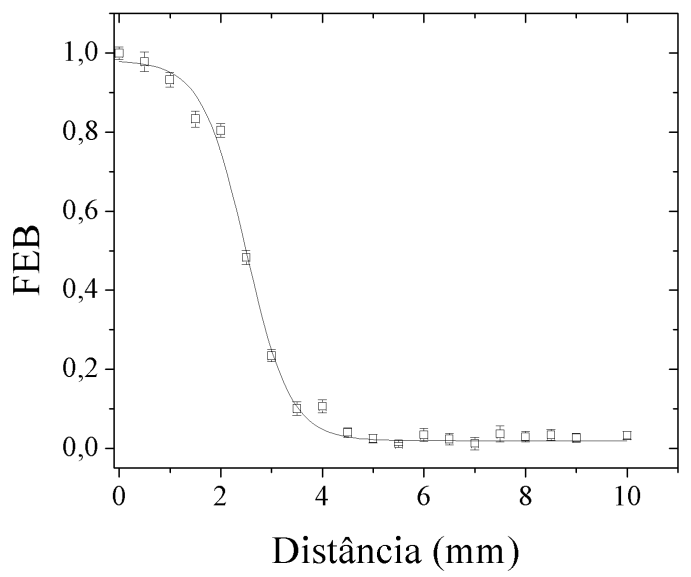

Figura 3.8. Perfil do sinal do dosímetro de antraceno ao medir a descontinuidade causada pela borda de uma blindagem posicionada no centro do campo do feixe de radiação (função de espalhamento de borda).

Da Figura 3.8 a resolução espacial foi obtida utilizando o método da borda, pelo qual obtém-se a distância em que o sinal diminui de $90 \%$ à $10 \%$. Para se obter um valor mais confiável possível, os dados foram ajustados por uma função senóide, e dela obteve-se a resolução espacial de 2,02 $\pm 0,07 \mathrm{~mm}$. A partir da derivada de primeira ordem em relação à distância do perfil da Figura 3.8 é possível obter o perfil equivalente à FEL, apresentada na Figura 3.9.

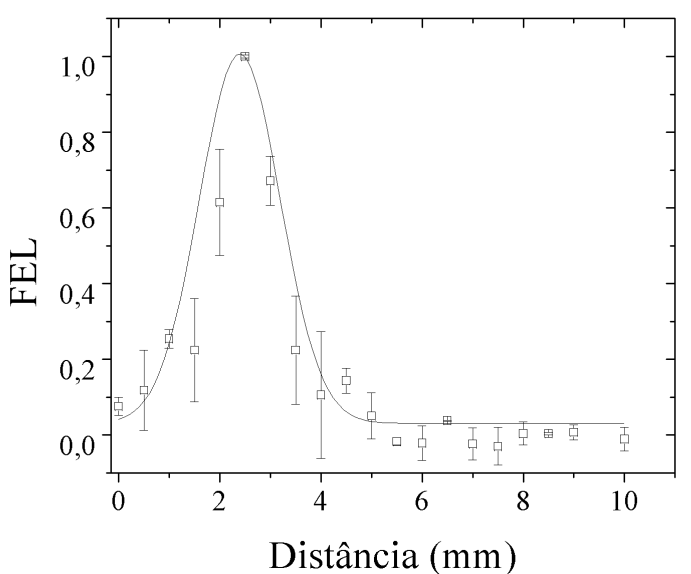

Figura 3.9. Função de espalhamento de linha obtida através da derivada de primeira ordem em relação à distância da FEB na Figura 3.8.

A partir do ajuste gaussiano dos pontos na Figura 3.9 o valor de resolução 
espacial obtido foi de 1,88 $\pm 0,07 \mathrm{~mm}$, inferido através da largura à meia altura da função. A função de transferência de modulação (MTF), obtida através da transformada de Fourier da FEL (Figura 3.9) é apresentada na Figura 3.10.

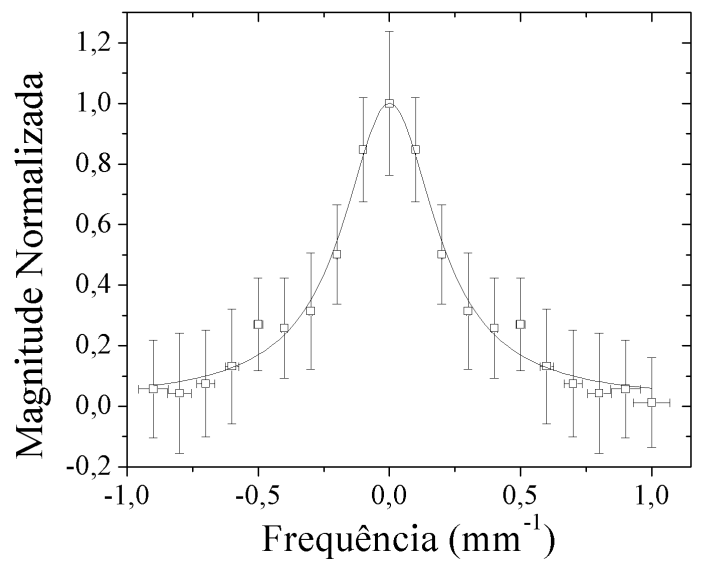

Figura 3.10. Função de transferência de modulação do perfil de borda da Figura 3.9.

Na Figura 3.10 é possível observar que os valores das incertezas se apresentam ampliados, sendo a maior igual a $24 \%$. Isso ocorre porque para a obtenção da MTF operações de derivação e integração são realizadas, constituindo numa limitação desse método [43]. Como apresentada no Capítulo 2, a MTF representa o contraste do sinal em função da frequência espacial dada em ciclos $/ \mathrm{mm}$. Da MTF normalizada na Figura 3.10, para o valor de contraste de 10\%, tem-se a resolução espacial de 1,43 $\pm 0,07 \mathrm{~mm}$, considerando a curva ajustada. Uma vez que a a resolução espacial neste trabalho está relacionada com o tamanho do detector [14], na Tabela 3.2 constam as diferenças encontradas entre os três métodos de avaliação e a dimensão da cápsula interna do cintilador $(1,6 \mathrm{~mm})$. 
Tabela 3.2. Relação entre os valores de resolução espacial obtidos com com os diferentes métodos e a dimensão do detector.

\begin{tabular}{ccccc}
\hline & FEB & FEL & MTF & $1,6 \mathrm{~mm}$ \\
\hline \hline FEB & $1,00 \pm 0,08$ & $1,07 \pm 0,08$ & $1,41 \pm 0,11$ & $1,26 \pm 0,10$ \\
FEL & $0,93 \pm 0,1$ & $1,00 \pm 0,08$ & $1,31 \pm 0,1$ & $1,18 \pm 0,09$ \\
MTF & $0,71 \pm 0,06$ & $0,76 \pm 0,06$ & $1,00 \pm 0,09$ & $0,89 \pm 0,07$ \\
\hline
\end{tabular}

Pela Tabela 3.2 é possível averiguar que o método que resultou no valor de resolução espacial mais próximo à dimensão do detector foi o da MTF, com uma diferença entre os valores de 11\%. O valor obtido de resolução espacial do dosímetro de antraceno permite que ele possa ser aplicado em radiocirurgia ou em outras medidas em que alta resolução espacial seja necessária. 
4 CONClusões 


\section{Capítulo}

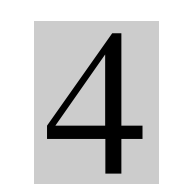

\section{CONCLUSÃO}

Este trabalho teve como objetivo a caracterização do dosímetro cintilador de antraceno, uma vez que sua aplicabilidade na radioterapia já havia se mostrado promissora [13]. Levando em consideração as características gerais que devem ser conhecidas ao utilizar um dosímetro no controle de qualidade de tratamentos radioterápicos, os experimentos neste trabalho foram realizados à fim de analisar as dependências do seu sinal em função da sua granulosidade, diâmetro interno de sua cápsula, dose absorvida, taxa de dose absorvida, energia do feixe de fótons e resolução espacial.

A dependência do sinal do dosímetro de antraceno em função da sua granulosidade foi obtido irradiando-se amostras com dimensões médias de grânulos de 0,$040 ; 0,093 ; 0,116 ; 0,165$ e 0,300 $\mathrm{mm}$. Pelo comportamento dessa dependêcia foi possível observar o aumento do sinal com o tamanho do grânulo, possivelmente devido à quantidade de interfaces grânulo-ar presentes nas amostras. Quando menor o tamanho dos grânulos de uma determinada amostra, maior o espalhamento da luz emitida pelo cintilador nas interfaces, resultando na diminuição da intensidade da luz a ser transportada pela fibra óptica. A dimensão média dos grânulos que forneceram o maior sinal foi de $0,3 \mathrm{~mm}$.

A dependência do sinal do dosímetro com o diâmetro interno da cápsula foi analisada irradiando-se o cintilador, com dimensões médias de grânulos de 0,3 mm, encapsulado em cilindros com 1,2 mm de comprimento e diâmetros de 0,$8 ; 1,0 ; 1,2$; 1,3; 1,4 e 1,6 mm. O sinal obtido aumentou com o tamanho do diâmetro interno (d) da cápsula proporcionalmente à $d^{3}$. Este comportamento está de acordo com o fato de que o sinal é proporcional ao volume do material irradiado, e também que 
o volume de um cilindro com comprimento constante aumenta com o cubo de seu diâmetro. No entanto, devido ao cone de aceitação da fibra óptica, definido por sua abertura numérica, esse comportamento possui um limite a partir do qual o sinal permanece constante, independente do aumento do diâmetro.

A curva de calibração do dosímetro foi obtida irradiando com feixes do ${ }^{60} \mathrm{Co}$ com doses de 0,03 à 2 Gy, previamente calibrados com câmara de ionização. O sinal em função da dose absorvida do cintilador apresentou um comportamento linear com sensibilidade de $2,310^{-4} \mathrm{C} / \mathrm{Gy}$.

O sinal do dosímetro apresentou independência com a taxa de dose absorvida. Os dados apresentados no trabalho foram corrigidos para serem independentes do quadrado da DFD da fonte de ${ }^{60}$ Co. As incertezas significativas, observadas para as taxas de dose absorvida menores, são devidas possivelmente à dificuldade em se posicionar o dosímetro no centro do campo de irradiação.

A dependência energética do sinal do dosímetro de antraceno foi analisada irradiando-o com feixes calibrados de ${ }^{60} \mathrm{Co},{ }^{137} \mathrm{Cs}$ e raios X. Observou-se o aumento linear do sinal com a energia do feixe para raios $\mathrm{X}$, e um desvio da linearidade para as energias maiores.

A resolução espacial do dosímetro de antraceno foi inferida a partir de três métodos equivalentes e relacionados. Para o método da função espalhamento de borda, tomando a distância na qual o sinal diminui de $90 \%$ à 10\%, obteve-se o valor de resolução espacial de 2,02 $\pm 0,07 \mathrm{~mm}$. Para o método da largura a meia altura da função de espalhamento linear, obtida da derivada da função de borda, o valor obtido foi de 1,88 $\pm 0,07 \mathrm{~mm}$. Para o método da MTF, no qual aplica-se a transformada de Fourier na função de linha, o valor foi obtido de resolução espacial (no contraste de

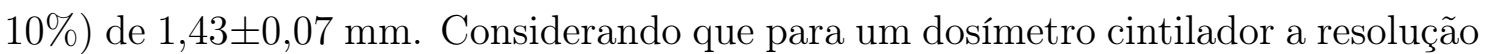
espacial está relacionada com seu tamanho físico, e nas medidas da resolução espacial utilizou-se uma cápsula cilíndrica com diâmetro interno de 1,6 mm, o método que resultou num valor mais próximo ao tamanho físico do dosímetro foi o da MTF, com diferença de $11 \%$.

A realização deste trabalho permitiu conhecer melhor o comportamento do dosímetro de antraceno, com relação à dependência do sinal com sua granulosidade, seu diâmetro da cápsula cilíndrica, dose absorvida, taxa de dose absorvida, 
energia do feixe de fótons e sua resolução espacial. Dos resultados obtidos com os experimentos realizados, podemos inferir que o dosímetro de antraceno pode ser utilizado tanto no controle de qualidade da radioterapia, incluindo técnicas como radiocirurgia, quanto em técnicas que utilizam energias mais baixas como radiodiagnóstico. Assim acredita-se que a utilização do dosímetro de antraceno em trabalhos futuros poderá ser realizada de maneira mais adequada com relação aos estudos aqui apresentados. 


\section{REFERÊNCIAS BIBLIOGRÁFICAS}

1 ATTIX, F. Introduction to Radiological Physics and Radiation Physics.

Weinheim: Wiley-VCH, 2004. xi, 8, 9, 10, 11, 12, 19

2 KNOLL, G. F. Radiation Detection and Measurement. USA: John Wiley \& Sons, 1989. xi, 3, 7, 9, 12, 13, 14, 15

3 (ICRU)REPORT24. Determination of Absorbed Dose in a Patient Irradiated by Beams of X and Gamma Rays in Radiotherapy Procedures. Oxford, 1976. 2, 6, 11

4 BEDDAR, A. S.; MACKIE, T. R.; ATTIX, F. H. Water-equivalent plastic scintillation detectors for high-energy beam dosimetry .2. properties and measurements. Physics In Medicine and Biology, v. 37, n. 10, p. 1901-1913, 1992. 2,20

5 BEDDAR, A. S.; MACKIE, T. R.; ATTIX, F. H. Water-equivalent plastic scintillation detectors for high-energy beam dosimetry .1. physical characteristics and theoretical considerations. Physics In Medicine and Biology, v. 37, n. 10, p. 1883-1900, 1992. 2, 20

6 PERERA, H.; Williamson, J. F.; MONThOFER, S. P.; BINnS, W. R.; KLARMANN, J.; FULLER, G. L.; WONG, J. W. Rapid 2-dimensional dose measurement in brachytherapy using plastic scintillator sheet - linearity, signal-to-noise ratio, and energy response characteristics. International Journal of Radiation Oncology Biology Physics, v. 23, n. 5, p. 1059-1069, 1992. 2

7 WELlS, C. M. M.; MACKIE, T. R.; PODGORSAK, M. B.; HOLMES, M. A.; PAPANIKOLAOU, N.; RECKWERDT, P. J.; CYGLER, J.; ROGERS, D. W. O.; BIELAJEW, A. F.; SCHMIDT, D. G.; MUEHLENKAMP, J. K. Measurements 
of the electron dose distribution near inhomogeneities using a plastic scintillation detector. International Journal of Radiation Oncology Biology Physics, v. 29, n. 5, p. $1157-1165,1994.2$

8 JORDAN, K. J. Evaluation of ruby as a fluorescent sensor for optical fiber-based radiation dosimetry. Fluorescence Detection Iv, Proceedings of, v. 2705, p. 170-178, 1996. 2

9 FLUHS, D.; HEINTZ, M.; INDENKAMPEN, F.; WIECZOREK, C.;

KOLANOSKI, H.; QUAST, U. Direct reading measurement of absorbed dose with plastic scintillators - the general concept and applications to ophthalmic plaque dosimetry. Medical Physics, v. 23, n. 3, p. 427-434, 1996. 2

10 LETOURnEAU, D.; POULIOT, J.; ROY, R. Miniature scintillating detector for small field radiation therapy. Medical Physics, v. 26, n. 12, p. 2555-2561, 1999. 2,20

11 FOWLER, J. M.; ROOS, C. E. Response of anthracene and stilbene to low-energy protons and x-rays. Physical Review, v. 98, n. 4, p. 996-999, 1955. 3

12 BRANNEN, E.; OLDE, G. L. Response of organic scintillators to electron energy deposited in them. Radiation Research, Radiation Research Soc, v. 16, n. 1, p. $1-6,1962.3$

13 RUBO, R. A. Dosimetro de cintilação de antraceno para uso na dosimetria de megavoltagem. Dissertação (Mestrado) - Faculdade de Filosofia Ciências e Letras da Universidade de São Paulo, 2001. 3, 17, 25, 37, 44

14 SMITH, S. W. The Scientist and Engineer's Guide to Digital Signal Processing. 1. ed. [S.l.]: California Technical Pub, 1997. 4, 28, 29, 31, 41

15 PODGORSAK, E. B. Radiation Oncology Physics: A Handbook for Teachers and Students. Vienna: IAEA, 2005. 6, 12, 13

16 KHAN, F. M. The Physics of Radiation Therapy. USA: Lippincott Williams \& Wilkins, 2003. 7, 12, 16 
17 BEDDAR, A. S. A new scintillator detector system for the quality assurance of co-60 and high-energy therapy machines. Physics In Medicine and Biology, v. 39, n. 2 , p. $253-263,1994.7$

18 BEDDAR, A. S.; KINSELlA, T. J.; IKHLEF, A.; SIBATA, C. H. A miniature "scintillator-fiberoptic-pmt"detector system for the dosimetry of small fields in stereotactic radiosurgery. Ieee Transactions On Nuclear Science, Ieee-inst Electrical Electronics Engineers Inc, v. 48, n. 3, p. 924-928, jun. 2001. 7

19 BEDDAR, A. S. Water equivalent plastic scintillation detectors in radiation therapy. Radiation Protection Dosimetry, v. 120, n. 1-4, p. 1-6, 2006.7

20 JOHnS, H. E.; CUNnINGHAM, J. R. The Physics of Radiology. Springfield: Charles C Thomas, 1983. 10

21 BEUTEL J; KUNDEL, H. L. V. R. L. Handbook of Medical Imaging, Volume 1. Physics and Psychophysics. Bellingham: SPIE Publications, 2000. 11

22 TURNER, J. E. Interaction of ionizing radiation with matter. Health Physics, Lippincott Williams \& Wilkins, v. 88, n. 6, p. 520-544, jun. 2005. 11

23 YIN, Y.; LAMBERT, J.; MCKENZIE, D. R.; SUCHOWERSKA, N. Real-time monitoring and diagnosis of scintillation dosimeters using an ultraviolet light emitting diode. Physics In Medicine and Biology, v. 53, n. 9, p. 2303-2312, 2008. 13

24 CLARKE, H. B.; SIMPSON, O.; NORTHROP, D. C. Scintillation phenomenon in anthracene .1. radiation damage. Proceedings of the Physical Society of London, v. 79, n. 508, p. $366-\&, 1962.15,17$

25 HUBBEL, J. H.; SELTZER, S. M. Tables of X-Ray Mass Attenuation Coefficients and Mass Energy-Absorption Coefficients from $1 \mathrm{keV}$ to $20 \mathrm{MeV}$ for Elements $Z=1$ to 92 and 48 Additional Substances of Dosimetric Interest. [S.1.], 2004. 16,28

26 BIRKS, J. B. Scintillation efficiency of anthracene crystals. Proceedings of the Physical Society of London Section A, v. 63, n. 371, p. 1294-1295, 1950. 17 
27 BIRKS, J. B.; BROOKS, F. D. Scintillation response of anthracene to 6-30 kev photoelectrons. Proceedings of the Physical Society of London Section B, v. 69, n. 7, p. $721-730,1956.17$

28 BIRKS, J. B.; WRIGHT, G. T. Fluorescence spectra of organic crystals. Proceedings of the Physical Society of London Section B, Iop Publishing Ltd, v. 67, n. 417, p. $657-663,1954.17$

29 BEDDAR, A. S. Water-equivalent plastic scintillation detector for high-energy photon and electron beams. Tese (Doutorado) - University of Wisconsin, 1990. 17

30 NETTO, A. D. P.; MOREIRA, J. C. Avaliação da comtaminação humana por hidrocarbonetos policíclicos aromáticos (HPAS) e seus derivados nitratos (NHPAS): Uma revisão metodológica. Quimica Nova, v. 23, p. 765-773, 2000. 17

31 EUROPEAN CHEMICALS AGENCY. Support Document for Identification of Anthracene as a Substance of Very High Concern. Helsinki, 2008. 17

32 MARCUSE, D. Principles of Optical Fiber Measurements. New York: Academic Press, 1981. 19

33 TABINI, R.; NUnES, D. Fibras Ópticas. São Paulo: Editora Érica, 1999. 19

34 BEDDAR, A. S.; MACKIE, T. R.; ATTIX, F. H. Cerenkov light generated in optical fibers and other light pipes irradiated by electron-beams. Physics In Medicine and Biology, v. 37, n. 4, p. 925-935, 1992. 19

35 JELLY, J. V. Cerenkov Radiation and its Applications. London: Pergamon Press, 1958. 19

36 BEDDAR, A. S.; SUCHOWERSKA, N.; LAW, S. H. Plastic scintillation dosimetry for radiation therapy: minimizing capture of cerenkov radiation noise. Physics In Medicine and Biology, v. 49, n. 5, p. 783-790, 2004. 20

37 ARCHAMBAULT, L.; BEDDAR, A. S.; GINGRAS, L.; ROY, R.; BEAULIEU, L. Measurement accuracy and cerenkov removal for high performance, high spatial resolution scintillation dosimetry. Medical Physics, v. 33, n. 1, p. 128-135, 2006. 20 
38 Clift, M. A.; JOHNSTON, P. N.; WEBB, D. V. A temporal method of avoiding the cerenkov radiation generated in organic scintillator dosimeters by pulsed mega-voltage electron and photon beams. Physics In Medicine and Biology, v. 47, n. 8 , p. $1421-1433,2002.20$

39 DEBOER, S. F.; BEDDAR, A. S.; RAWLINSON, J. A. Optical filtering and spectral measurements of radiation-induced light in plastic scintillation dosimetry. Physics In Medicine and Biology, v. 38, n. 7, p. 945-958, 1993. 20

40 AYOTTE, G.; ARCHAmBAult, L.; GINGRAS, L.; LACROIX, F.; BEDDAR, A. S.; BEAULIEU, L. Surface preparation and coupling in plastic scintillator dosimetry. Medical Physics, v. 33, n. 9, p. 3519-3525, 2006. 25

41 DIAS, J. A. Análise sedimentar e o conhecimento dos sistemas marinhos. 2004. 25

42 LAMBERT, J.; YIN, Y.; MCKENZIE, D. R.; LAW, S.; SUCHOWERSKA, N. Cerenkov-free scintillation dosimetry in external beam radiotherapy with an air core light guide. Physics In Medicine and Biology, v. 53, n. 11, p. 3071-3080, jun. 2008. 38

43 BARAKAT, R. Determination of the optical transfer function directly from the edge spread function. Journal of the optical Society of America, v. 55, p. 1217-1221, 1965. 41

44 ORGANICS, A. Material Safety Data Sheet. 2009.

Http://www.wku.edu/msds/docs/30.pdf. 53 


\section{APÊNDICE}

\section{APÊNDICE I - CUIDADOS EM RELAÇÃO AO ANTRACENO}

\section{A.1 Controle de Exposição e Proteção Pessoal}

Sistema de Ventilação: um sistema de exaustão local ou geral é recomendado para manter a exposição ao usuário a menor possível.

Respiradores pessoais: para condições de uso em que há exposição a poeira ou vapor, um respirador de meia face contra poeira e vapor é efetivo.

Proteção da Pele: use luvas protetoras e roupas limpas que cubram todo o corpo.

Proteção dos Olhos: use óculos químico-protetores. Mantenha uma fonte para lavar os olhos na área de trabalho.

\section{A.2 Efeitos potenciais à saúde}

Inalação: Causa irritação ao trato respiratório.

Ingestão: Causa irritação à área gastrointestinal.

Contato com a pele: Causa irritação à pele. Fotosensível.

Contato com os olhos: Causa irritação, vermelhidão e dor.

\section{A.3 Medidas de Primeiros Socorros}

Inalação: Remover o indivíduo exposto ao ar livre. Se não estiver respirando, fazer respiração artificial. Se respirar com dificuldade, dê oxigênio. Procure ajuda médica. 
Ingestão: Dê quantias grandes de água para beber. Nunca dê algo pela boca para uma pessoa inconsciente. Procure ajuda médica.

Contato com a pele: Lave imediatamente em água corrente por, pelo menos, 15 minutos. Remova a roupa contaminada e os sapatos. Procure ajuda médica se irritação desenvolve ou persiste.

Contato com os olhos: Lave imediatamente com água corrente por, pelo menos 15 minutos, abrindo e fechando ocasionalmente as pálpebras. Procure ajuda médica imediatamente.

As informações para esse Apêndice foram retirados de uma cartela laboratorial de dados [44]. 